ARTICLE

https://doi.org/10.1038/s41467-018-07758-x

\title{
Stabilization of cytokine mRNAs in iNKT cells requires the serine-threonine kinase IRElalpha
}

Srinath Govindarajan ${ }^{1,2}$, Djoere Gaublomme ${ }^{1,2}$, Renée Van der Cruyssen ${ }^{1,2}$, Eveline Verheugen ${ }^{1,2}$, Sofie Van Gassen ${ }^{3,4}$, Yvan Saeys ${ }^{3,4}$, Simon Tavernier ${ }^{5,6}$, Takao Iwawaki ${ }^{7}$, Yehudi Bloch ${ }^{8,9}$, Savvas.N. Savvides ${ }^{8,9}$, Bart N. Lambrecht $5,6,10$, Sophie Janssens ${ }^{11,12}$, Dirk Elewaut ${ }^{1,2} \&$ Michael B. Drennan (10 1,2

Activated invariant natural killer T (iNKT) cells rapidly produce large amounts of cytokines, but how cytokine mRNAs are induced, stabilized and mobilized following iNKT activation is still unclear. Here we show that an endoplasmic reticulum stress sensor, inositol-requiring enzyme $1 \alpha(\mathrm{IRE} 1 \alpha)$, links key cellular processes required for iNKT cell effector functions in specific iNKT subsets, in which TCR-dependent activation of IRE1 $\alpha$ is associated with downstream activation of p38 MAPK and the stabilization of preformed cytokine mRNAs. Importantly, genetic deletion of IRE1 $\alpha$ in iNKT cells reduces cytokine production and protects mice from oxazolone colitis. We therefore propose that an IRE1 $\alpha$-dependent signaling cascade couples constitutive cytokine mRNA expression to the rapid induction of cytokine secretion and effector functions in activated iNKT cells.

\footnotetext{
${ }^{1}$ Unit for Molecular Immunology and Inflammation, VIB Center for Inflammation Research, Technologiepark 927, 9052 Zwijnaarde (Ghent), Belgium.

${ }^{2}$ Department of Rheumatology, Ghent University, Ghent University Hospital, Ghent 9000, Belgium. ${ }^{3}$ Department of Applied Mathematics, Computer Science and Statistics, Ghent University, Ghent 9000, Belgium. ${ }^{4}$ Data Mining and Modeling for Biomedicine, VIB Center for Inflammation Research, Technologiepark 927, 9052 Zwijnaarde (Ghent), Belgium. ${ }^{5}$ Laboratory of Immunoregulation and Mucosal Immunology, VIB Center for Inflammation Research, Technologiepark 927, 9052 Zwijnaarde (Ghent), Belgium. ${ }^{6}$ Department of Respiratory Medicine, Ghent University, Ghent University Hospital, 9000 Ghent, Belgium. ${ }^{7}$ Division of Cell Medicine, Department of Life Science, Medical Research Institute, Kanazawa Medical University, Kanazawa 920 0856, Japan. ${ }^{8}$ Unit for Structural Biology, Department of Biochemistry and Microbiology, Ghent University, Technologiepark 927, 9052 Zwijnaarde (Ghent), Belgium. ${ }^{9}$ Unit for Structural Biology, VIB Center for Inflammation Research, Technologiepark 927, 9052 Zwijnaarde, (Ghent), Belgium. ${ }^{10}$ Department of Pulmonary Medicine, Ghent University, ErasmusMC, Rotterdam 2040, Netherlands. ${ }^{11}$ Laboratory of ER Stress and Inflammation, VIB Center for Inflammation Research, Technologiepark 927, 9052 Zwijnaarde (Ghent), Belgium. ${ }^{12}$ Department of Internal Medicine and Pediatrics, Ghent University, Ghent 9000 , Belgium. These authors contributed equally: Dirk Elewaut, Michael B. Drennan. Correspondence and requests for materials should be addressed to D.E. (email: Dirk.Elewaut@ugent.be)
} 
nvariant natural killer T (iNKT) cells are characterized as an innate $\mathrm{T}$-cell subset that recognizes glycolipid antigens presented by CD1d, an MHC class I-related molecule ${ }^{1}$. A hallmark feature of iNKT cells is their ability to rapidly produce and secrete immunomodulatory cytokines following T-cell receptor (TCR) ligation, implicating them in a range of inflammatory, allergic, and autoimmune diseases ${ }^{1}$. Although this functional aspect of iNKT cell biology is not fully understood, it has been suggested that the presence of preformed cytokine mRNAs as well as histone acetylation of distinct cytokine loci facilitate rapid iNKT cell cytokine production ${ }^{2,3}$. However, beyond such studies, it has proved difficult to investigate the potential regulatory mechanisms involved in iNKT cell cytokine production as many of these signaling pathways also control iNKT cell development, maturation, and survival ${ }^{1,4}$. We therefore sought to investigate whether iNKT cells utilize components of the unfolded protein response (UPR) to accommodate the rapid increase in cytokine production following activation as has been observed for the production of antibodies during plasma cell differentiation ${ }^{5,6}$.

UPR is an intracellular signal transduction pathway conserved from yeast to mammals that senses perturbations in protein folding, protein synthesis and/or calcium homeostasis within the endoplasmic reticulum (ER). In mammals, the UPR consists of the three proximal ER stress sensors; inositol-requiring enzyme 1a (IRE1 $\alpha)$, ER-resident protein kinase R-like endoplasmic reticulum kinase (PERK), and activating transcription factor 6 (ATF6) that collectively function to promote ER homeostasis by increasing protein folding capacity and protein biosynthesis within the ER during stress ${ }^{7}$. Prolonged or severe ER stress that cannot be resolved by induction of the UPR is widely considered to trigger apoptosis and inflammation and is involved in the development of a number of human diseases characterized by a metabolic or inflammatory pathology ${ }^{8}$.

IRE1 $\alpha$ is a type I ER-resident transmembrane protein that comprises an ER luminal and cytosolic domain with both serinethreonine kinase and endoribonuclease activity ${ }^{9}$. During ER stress, oligomerization of the luminal domain of IRE1 $\alpha$ results in autophosphorylation of the cytosolic domain and activation of a sequence-specific endoribonuclease (RNase) which recognizes and cleaves an intron from pre-mRNA encoding the bZIP transcription factor XBP $1^{10}$. Translocation of cleaved or spliced XBP1 (XBP1s) to the nucleus is associated with the upregulation of ER chaperone proteins and enzymes which function to increase protein folding capacity and quality control within the $\mathrm{ER}^{11,12}$. The RNase domain of IRE1a also targets and degrades distinct mRNAs containing a consensus sequence in a process termed regulated IRE1 $\alpha$-dependent decay (RIDD) ${ }^{13}$, further reducing protein translocational load during ER stress. In addition to these functions, autophosphorylation of IRE1a during UPR is also associated with downstream c-Jun kinase (JNK) phosphorylation $^{14}$, which is proposed to promote apoptosis in cells unable to resolve ER stress ${ }^{15}$. ER stress however also activates additional ER stress sensors including the protein kinase PERK and the transcription factor ATF6 ${ }^{16,17}$. Here, the substrates for the protein kinase activity of PERK have been identified, namely the eukaryotic translation initiation factor $2 \alpha$ (eIF2 $\alpha$ ). EIF2 $\alpha$ has been shown to counteract the formation of reactive oxygen species and to inhibit cap-dependent mRNA translation ${ }^{18}$. ER stressmediated proteolysis of the ER luminal domain of ATF6 results in the liberation of a bZIP transcription factor that induces genes involved in ER chaperone function and ER-associated protein degradation (ERAD) ${ }^{17,19}$. Collectively, UPR therefore promotes ER homeostasis and cell survival by regulating an adaptive response at both the transcriptional as well as translational level. Irremediable ER stress is however associated with inflammatory signaling and the initiation of apoptosis ${ }^{15}$.
Although it is widely acknowledged that UPR regulates cellular survival during ER stress, several studies have shown that UPR is also required by $\mathrm{B}$ lymphocytes during plasma cell differentiation ${ }^{5,20}$. Here, XBP1s is required for the increased synthesis and secretion of Ig chains by plasma cells ${ }^{5,6}$, suggesting that IRE1 $\alpha$ is directly activated during B-cell differentiation. Similarly, T-cell differentiation following TCR ligation is associated with the activation of IRE1 $\alpha^{21}$, whereas PERK has been shown to control $\mathrm{T}$-cell effector functions by regulating the translation of distinct cytokine mRNAs ${ }^{22}$.

In this study, we demonstrate that defined iNKT sublineages constitutively express components of the UPR, and require IRE1a to stabilize cytokine mRNAs following activation both in vitro and in vivo. We propose that these findings represent a novel mechanism whereby IRE1a functions as a central regulator of cytokine production for specific iNKT subsets in vivo.

\section{Results}

IRE1a RNase domain is active within NKT1 and 17 sublineages. To assess steady-state UPR activity in $\mathrm{T}$ cells by flow cytometry, we analyzed expression of a variant of green fluorescent protein (FP) in $\mathrm{T}$ cells isolated from the thymus, spleen and liver of naïve ERAI-transgenic (ERAI ${ }^{\mathrm{FP} / \mathrm{WT}}$ ) mice ${ }^{23}$. We utilized ERAI ${ }^{\mathrm{FP} / \mathrm{WT}}$ mice as a UPR-specific reporter as they express a partial sequence of human XBP-1 that includes the sites at which IRE-1a splices XBP-1, fused to Venus fluorescent protein $\left(\right.$ Venus $^{\mathrm{FP}}$ ), which allows reporting of the IRE-1 $\alpha$ arm of the $\mathrm{UPR}^{23}$. Subsequent flow cytometric analysis of the T-cell compartment using a Self-Organizing Map (FlowSOM) ${ }^{24}$ visually defined specific T-cell lineages as a minimal spanning (MS) tree in which clusters of similar cells were represented as nodes within each T-cell subset (Fig. 1a, c, e). In this manner, the MS trees clearly identified distinct T-cell subsets within each organ as either double-negative (DN, green) or double-positive (DP, orange) thymocytes, $\mathrm{CD} 4^{+} \mathrm{T}$ cells (yellow), $\mathrm{CD}^{+}{ }^{+} \mathrm{T}$ cells (red), CD1d tetramer-negative NKT-like cells ${ }^{25}$ (light blue), iNKT cells (dark blue) and $\gamma \delta \mathrm{T}$ cells (purple), respectively (Fig. 1a, c, e). Venus $^{\mathrm{FP}}$ expression within each node was subsequently determined by computing the difference between Venus ${ }^{\mathrm{FP}}$ expression within $\mathrm{T}$ cells isolated from ERAI ${ }^{\mathrm{FP} / \mathrm{WT}}$ mice and background auto-fluorescence in $\mathrm{T}$ cells isolated from littermate control (ERAIWT/WT) mice. As is shown in Fig. 1b, d, $\mathrm{f}$, the majority of Venus $^{\mathrm{FP}}$ expression was found to be restricted to iNKT cells present in the spleen and liver; however, reporter expression was also detected within peripheral iNKT and $\gamma \delta$ T-cell lineages (Fig. 1c, e). Data visualization of Venus ${ }^{\mathrm{FP}}$ expression using the FlowSOM MS tree was therefore independently examined by analyzing the expression of spliced and unspliced XBP1 mRNA within FACS-sorted T-cell subsets isolated from thymus, spleen, and liver of wild-type mice. Here, qPCR analysis verified that splenic and hepatic iNKT cells expressed the highest level of IRE1 $\alpha$ RNase activity when compared to $\gamma \delta$ and T-cell lineages (Fig. 1g). A subsequent analysis of Venus ${ }^{\mathrm{FP}}$ expression within the NKT1, 2 and 17 sublineages as defined by the cell-surface markers CD27 and CD122 26,27 revealed selective expression of Venus $^{\mathrm{FP}}$ within the NKT1 and NKT17 sublineages, respectively (Fig. 1h). Notably, only NKT17 cells present in the spleen expressed Venus $^{\mathrm{FP}}$ whereas NKT2 cells isolated from the thymus, spleen, liver, popliteal lymph node (PLN) and mediastinal lymph node (MLN) did not (Fig. 1h). These results therefore show that a constitutively active IRE1 $\alpha$ RNase is present within the peripheral iNKT cell compartment and that splenic and hepatic NKT1 and NKT17 sublineages express the highest levels of XBP1s.

TCR ligation induces UPR in NKT1 and 17 sublineages. iNKT cells have been shown to be activated by signals emanating from their $\mathrm{TCR}^{1}$ as well as by cytokines such as IL-12 and type 1 

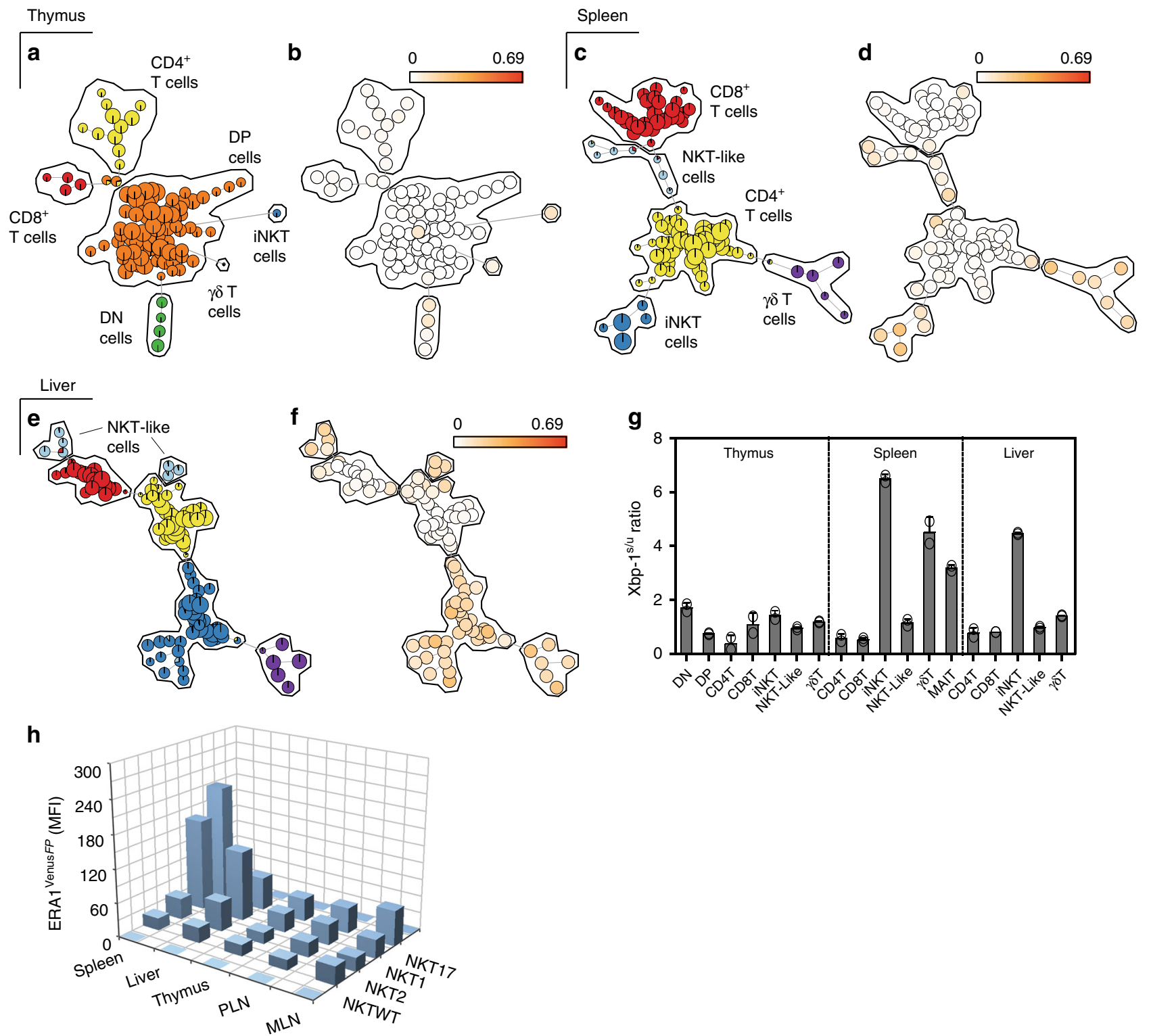

Fig. 1 Constitutive IRE1 $\alpha$ RNase activity in iNKT cells of naïve ERA1- mice. a-f Minimal spanning tree visualization of T-cell subsets by FlowSOM analysis. Manual gating results for $\mathbf{a}$ thymus, $\mathbf{b}$ spleen and $\mathbf{c}$ liver indicate which nodes correspond to the indicated T-cell subsets. Node size corresponds to the percentage of cells represented by each node. $\mathbf{b}, \mathbf{d}, \mathbf{f}$ Venus $\mathrm{FP}^{\mathrm{P}}$ expression within ERA1FP/WT and control ERA1WT/WT mice for thymus, spleen, and liver, respectively $(n=3)$. Data represent three independent experiments. $\mathbf{g}$ Xbp-1s/u mRNA ratio expressed by T-cell subsets isolated from thymus, spleen, and liver of C57BI/6 mice $(n=5)$. Bar chart represents two independent experiments pooled. $\mathbf{h}$ Venus ${ }^{\mathrm{PP}}$ MFI within NKT1, 2 and 17 cells isolated from thymus, spleen, PLN, MLN, and liver of ERA F FP/WT mice $(n=3)$. iNKTWT represents Venus ${ }^{\mathrm{FP}}$ MFI within control iNKT cells isolated from WT mice. Bar chart represents one of three independent experiments. T lymphocyte subsets in $(\mathbf{a}-\mathbf{g})$ are defined in Materials and Methods. Error bars show the mean \pm s.e.m

IFN $^{28,29}$. We initially examined the role of TCR-dependent signaling in regulating IRE1a RNase activity within iNKTs by stimulating splenic iNKT sublineages in vitro using anti-CD3/ CD28. For these experiments, splenic NKT1 ${ }^{\mathrm{a}}$, NKT1 ${ }^{\mathrm{b}}$, NKT2, and NKT17 sublineages were FACS sorted based on CD27 and CD122 cell-surface expression and expanded in vitro as has been previously reported 26,27 . Subsequent in vitro restimulation of iNKT sublineages revealed that TCR-dependent stimulation induced pronounced splicing of Xbp1 mRNA (Fig. 2a), as well as several UPR-associated mRNAs (Fig. 2b) within the NKT17 and NKT1, but not NKT2 sublineage cells. Importantly, we show that TCR-induced splicing of Xbp1 mRNA within restimulated iNKT cells (Fig. 2a) is associated with increased autophosphorylation of IRE1a (Fig. 2c), suggesting that TCR-mediated signaling within iNKT cells induces activation of the kinase domain of IRE1a. A subsequent analysis of the ability of additional stimuli to induce $X b p 1 \mathrm{mRNA}$ splicing within in vitro expanded iNKT cells revealed that neither cytokines such as IL12 p70 and IFN $\beta$, nor Toll-like receptor (TLR) agonists such as lipopolysaccharide (LPS) or Poly (I:C) induced significant IRE1a RNase activity above that observed for medium controls (Fig. 2d). These results were confirmed in vivo using ERAI ${ }^{\mathrm{FP} / \mathrm{WT}}$ mice (Fig. $2 \mathrm{e}-\mathrm{h}$ ). Here, intraperitoneal (i.p.) administration of $\alpha$ galactosylceramide ( $\alpha$-GalCer), a TCR ligand, significantly increased Venus ${ }^{\mathrm{FP}}$ expression within splenic and hepatic iNKT cells when compared to vehicle controls (Fig. $2 \mathrm{e}-\mathrm{h}$ ). In contrast, induction of type 1 IFN following administration of Poly (I:C) failed to modulate expression of Venus $^{\mathrm{FP}}$ within iNKTs 


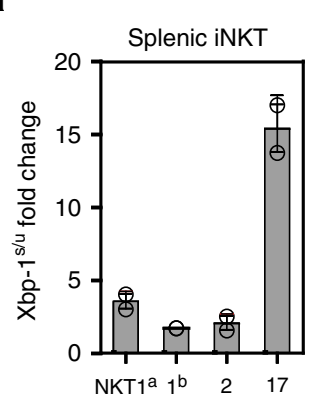

d

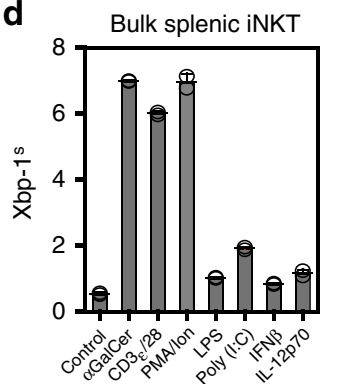

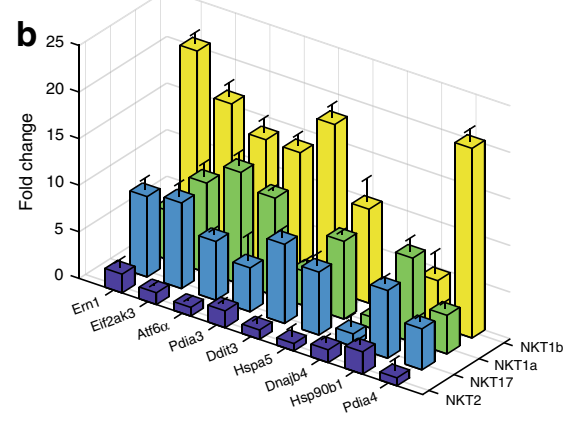

C

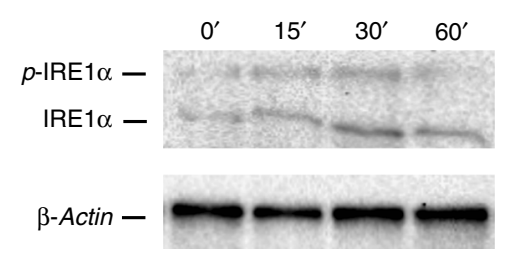

e

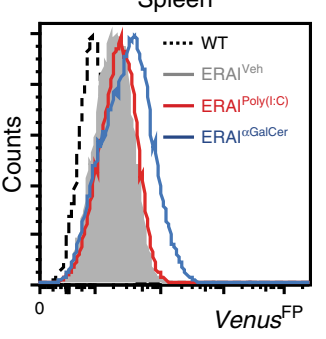

f

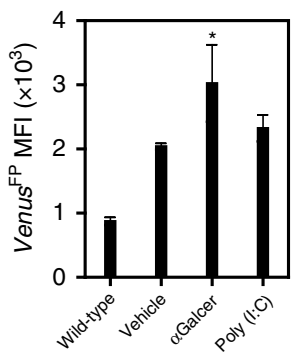

g

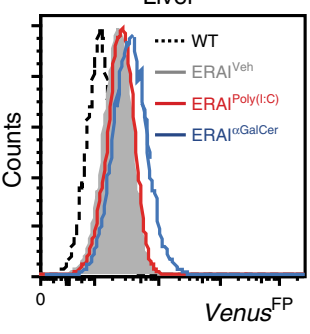

h

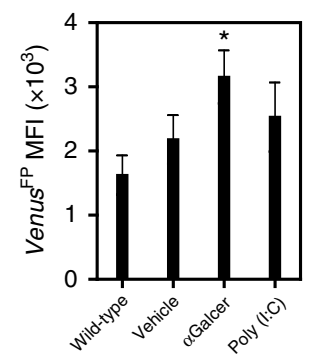

Fig. 2 TCR-dependent stimuli regulate activation of UPR in NKT sublineages. Expanded splenic NKT cell sublineages were restimulated with anti-CD3/ CD28 $\left(3 \mu \mathrm{g} \cdot \mathrm{ml}^{-1} / 5 \mu \mathrm{g} \cdot \mathrm{ml}^{-1}\right)$ for $3 \mathrm{~h}$ and fold induction of Xbp-1s/u (a) and ER chaperone mRNAs (b) in stimulated versus resting cells was assessed by qPCR $(n=3)$. Bar chart represents two independent experiments pooled. c Analysis of phosphorylated IRE1 $\alpha$ and total IRE1 $\alpha$ in bulk expanded splenic iNKT cells restimulated with $\alpha-C D 3 \varepsilon / C D 28$ for the indicated times via phos-tag immunoblot assay. $\beta$-Actin represents the loading control. Results represent one of two independent experiments. $\mathbf{d}$ qPCR analysis of XBP1s in expanded splenic iNKT cells stimulated with $\alpha-\mathrm{GalCer}$ (100 ng/ml), anti-CD3/ CD28 $\left(3 \mu \mathrm{g} \cdot \mathrm{ml}^{-1} / 5 \mu \mathrm{g} \cdot \mathrm{ml}^{-1}\right)$, PMA/lonomycin $\left(1 \mu \mathrm{M} / 200 \mathrm{ng} \cdot \mathrm{ml}^{-1}\right)$, LPS $(20 \mathrm{ng} / \mathrm{ml})$, Poly(I:C) $(20 \mathrm{ng} / \mathrm{ml}), \mathrm{IFN} \beta(100 \mathrm{U} / \mathrm{ml})$, IL-12p70 (20 ng/ml) or medium $(n=3)$. Bar chart represents two independent experiments pooled. $\mathbf{e}-\mathbf{h}$ Control and ERA1FP/WT mice were injected with either vehicle, $\alpha$-GalCer or Poly $(\mathrm{I}: \mathrm{C})$ and iNKT cells were analyzed in spleen and liver $2 \mathrm{~h}$ later. Histograms and bar graphs represent Venus $\mathrm{FP}$ expression within iNKT cells isolated from the spleen and liver of WT (dashed line, $n=2$ ), vehicle-injected ERA1FP/WT (gray, $n=3$ ), $\alpha$-GalCer-injected ERA1 FP/WT (blue line, $n=3$ ) or Poly $(\mathrm{I}: \mathrm{C}$ )injected ERA ${ }^{F P} / \mathrm{WT}$ mice (red line, $n=3$ ) at $2 \mathrm{~h}$ postinjection. Histogram and bar chart represents one of three independent experiments. Error bars show the mean \pm s.e.m. ${ }^{\star} p<0.05$ determined by Mann-Whitney $U$ test

isolated from $\mathrm{ERAI} \mathrm{FP} / \mathrm{WT}$ mice (Fig. 2e-h). Thus, TCRdependent stimuli induce UPR and IRE1a RNase activity within the NKT1 and NKT17 sublineages, both in vitro and in vivo.

iNKT sublineage development is IRE1 $\alpha$-independent. IRE1a has previously been shown to be required in pre-B cells during Bcell receptor formation as well as for the secretion of immunoglobulins (Igs) during plasma cell differentiation ${ }^{5,30}$. In contrast, development and activation of the conventional T-cell compartment is unaltered in the absence of IRE1 $\alpha^{31}$, suggesting that IRE1a regulates lymphocyte development and function in a lineage-specific manner. We therefore sought to determine whether iNKT cell development required IRE1 $\alpha$ as iNKT cells express a constitutively active IREla RNase (Fig. 1), and upregulate spliced XBP1 mRNA following TCR stimulation (Fig. 2). To examine the requirement for IREla during iNKT cell development, we generated CD4 T-cell-specific IRE1 $\alpha$-deficient mice $\left(\mathrm{CD} 4^{\text {cre }}\right.$; IRE $\left.1 \alpha^{\Delta / \Delta}\right)$ by intercrossing CD4-cre transgenic mice with mice carrying a LoxP flanked IRE1 $\alpha$ allele. A subsequent analysis of the frequency and absolute cell counts of iNKT cells present in the thymus, spleen, and liver of $\mathrm{CD} 4^{\mathrm{cre}} ; \mathrm{IRE} 1 \alpha^{\Delta / \Delta}$ mice revealed no significant differences when compared to littermate IRE $1 a^{\mathrm{F} / \mathrm{F}}$ controls (Supplementary Fig. 1A, B), and the development and maturation of iNKT cell thymocytes from stage 1 $\left(\mathrm{CD} 44^{\mathrm{lo}} \mathrm{NK} 1.1^{-}\right)$to stage $3\left(\mathrm{CD} 44^{\mathrm{hi}} \mathrm{NK} 1.1^{\mathrm{hi}}\right)$ iNKT cells occurred normally in the absence of IRE1a (Supplementary Fig. 1C, D). Similarly, analysis of iNKT sublineage development using the transcription factors promyelocytic leukemia zinc finger (PLZF) and ROR $\gamma t$ revealed no significant differences in the frequency or absolute numbers of NKT1, NKT2 or NKT17 sublineages present in thymus, spleen, and liver of $\mathrm{CD} 4^{\text {cre }} ; \operatorname{IRE} 1 \alpha^{\Delta / \Delta}$ mice relative to controls (Supplementary Fig. 1E, F). To directly evaluate the proliferative capacity of iNKT cells in the absence of IRE1 $\alpha$, DNA labeling studies with BrdU were performed after administration of mice intraperitoneally with $\alpha$-GalCer. Analysis of iNKT cells expansion after 5 days postinjection with $\alpha$-GalCer revealed no significant differences between $\mathrm{CD} 4^{\mathrm{cre}} ; \mathrm{IRE} 1 \alpha^{\Delta / \Delta}$ mice when compared to littermate controls (Supplementary Fig. 1G). Thus, IREla serves a limited role in the selection, maturation, and lineage specification of the iNKT cell compartment in steady-state animals.

iNKT cell motility dynamics are IRE1 $\alpha$-independent. To further analyze potential differences between wild-type and IRE1 $\alpha$ deficient iNKT cells, intravital motility dynamics of hepatic iNKT cells were investigated using multiphoton microscopy. For these experiments $\mathrm{CD} 4^{\mathrm{cre}} ; \mathrm{IRE} 1 \alpha^{\Delta / \Delta}$ mice were backcrossed onto a CXCR6gfp/- background as this mouse line has previously been shown to be a reporter specific for hepatic iNKT cells ${ }^{1}$.

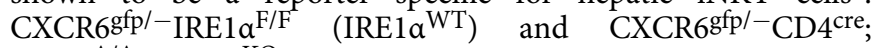
$I^{2} 1 a^{\Delta / \Delta}\left(\operatorname{IRE} 1 \alpha^{\mathrm{KO}}\right)$ mice were subsequently imaged for $2 \mathrm{~h}$ at steady-state until they received an i.v. injection with $\alpha$-GalCer, after which they were imaged for two more hours to capture the TCR-mediated cell arrest that follows iNKT cell activation ${ }^{32}$. The overall appearance and behavior of IRE1 $\alpha^{\mathrm{WT}}$ and IRE $1 a^{\mathrm{KO}}$ mice were very similar (Supplemental movies 1 and 2), apart from the sporadic presence of clusters of $\mathrm{GFP}^{+}$cells in the $\mathrm{KO}$ mice. We 
a

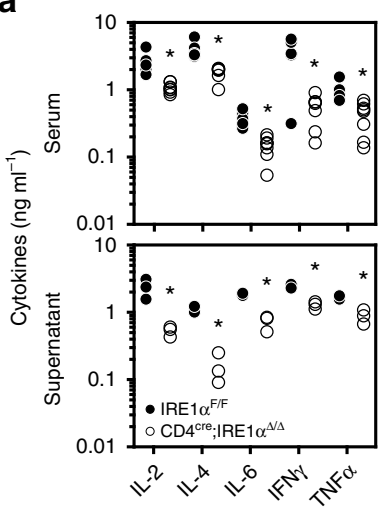

b

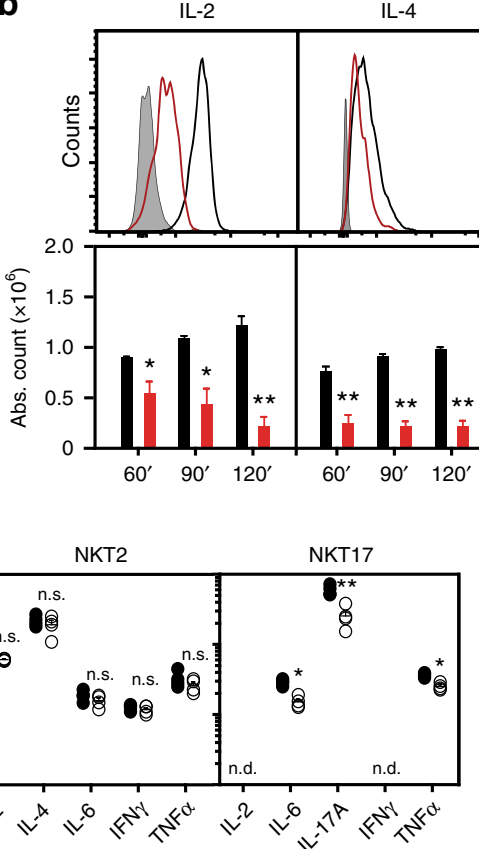

IL-6

IL-13

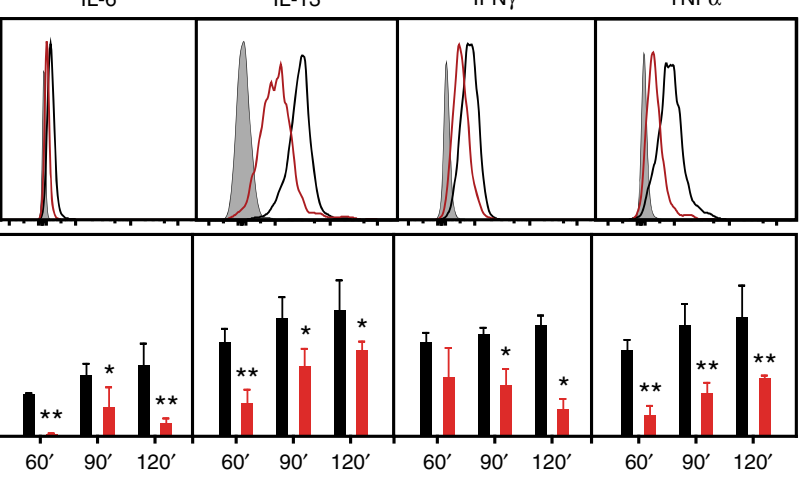

C
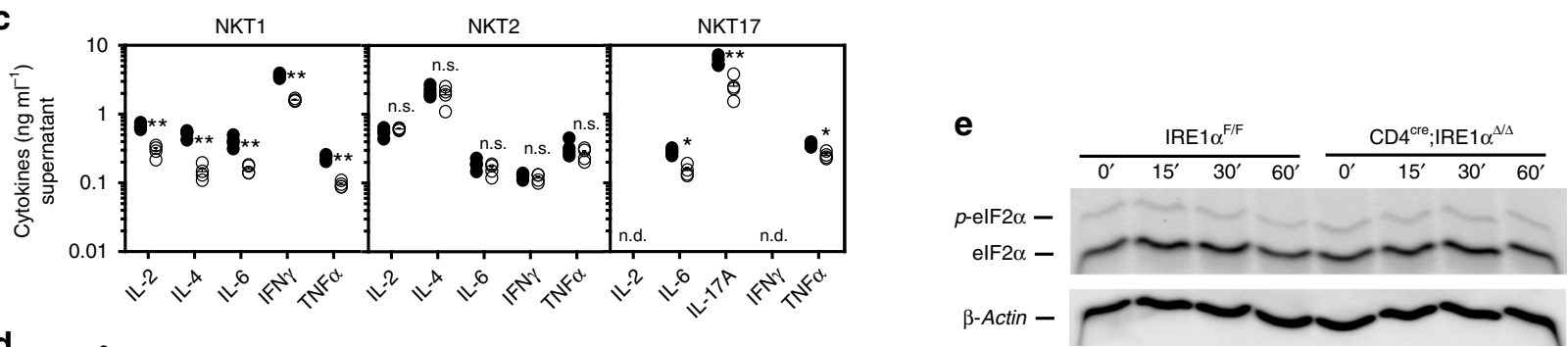

d

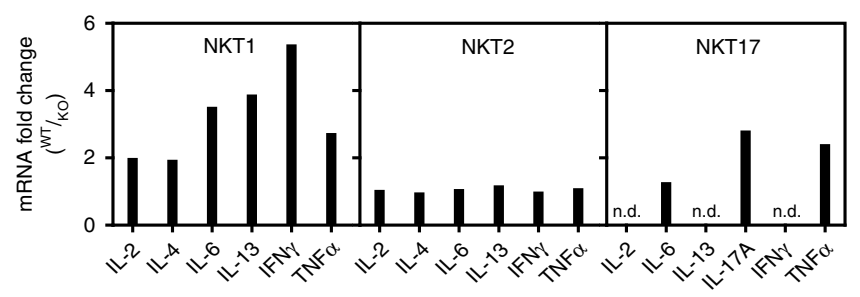

Fig. 3 Impaired cytokine production by IRE1 $\alpha$-deficient iNKT cells. a Cytokines measured in serum from control $(n=11)$ and CD4cre;IRE1 $\alpha^{\Delta / \Delta}(n=12)$ at $4 \mathrm{~h}$ post- $\alpha$-GalCer injection. Dot blots are representative of two independent experiments pooled. (Lower panel) Expanded iNKT splenocytes from control ( $n=$ 4) and CD4 ${ }^{\text {cre } ; I R E 1} 1 \alpha^{\Delta / \Delta}(n=4)$ mice were restimulated with anti-CD3/CD28 for $72 \mathrm{~h}$ and cytokines were measured in supernatant by ELISA. b FACS histograms (upper panel) and absolute cell counts (lower panel) of cytokine-positive splenic iNKT cells isolated from control (black line, $n=4)$ and CD4cre; $\operatorname{IRE} 1 \alpha^{\Delta / \Delta}$ (red line, $n=4$ ) mice following injection of vehicle (isotype, gray) or $\alpha$-GalCer at 60,90 , and 120 min postinjection, respectively. Histograms and bar charts are representative of two independent experiments. Supernatant cytokines (c) and cytokine mRNAs (d) from splenic NKT sublineages isolated from control $(n=4)$ and CD4cre; IRE1 $\alpha^{\Delta / \Delta}(n=4)$ mice following restimulation with anti-CD3/CD28 for $3 \mathrm{~h}$. qPCR data are represented as fold mRNA change in control versus knock-out (KO) cells. Dot blot and bar chart represents two independent experiments pooled. Phos-tag immunoblot analysis of

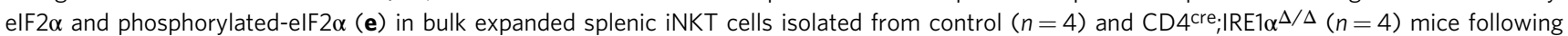
restimulation with anti-CD3/CD28 at indicated time points. $\beta$-Actin represents the loading control. Results are representative of two independent experiments. Error bars show the mean \pm s.e.m. ${ }^{\star} p<0.05,{ }^{\star \star} p<0.01$ determined by Mann-Whitney $U$ test and unpaired $t$ test; n.d. not detected; n.s. not significant

quantified the motility dynamics and showed that there was no significant difference in the average speed (Supplementary Fig. 2A), speed distribution (Supplementary Fig. 2B), cell track distribution (Supplementary Fig. 2C-F), displacement over time (Supplementary Fig. 2G), and confinement index (Supplementary Fig. $2 \mathrm{H})$ of $\mathrm{GFP}^{+}$cells in IRE1 $\alpha^{\mathrm{WT}}$ and IRE $1 \alpha^{\mathrm{KO}}$ mice, respectively. Plotting the squared displacement over time allows to differentiate between different types of migration, with a linear curve representing random movement, whereas for example an upwards curve reveals directed movement. The confinement index is a measure of the straightness of the cell tracks, with a low value indicating confined movement, possibly caused by interaction with neighboring cells. As expected, iNKT cells show a more confined movement following injection with $a$-GalCer. Overall, IRE1a does not appear to influence iNKT cell dynamics.

IRE1 $\alpha$ specifically regulates NKT1 and 17 cytokine production. To investigate whether UPR-mediated signaling regulates the rapid secretion of effector cytokines by iNKT cells, we injected control and $\mathrm{CD} 4^{\mathrm{cre}} ; \operatorname{IRE} 1 \alpha^{\Delta / \Delta}$ mice intraperitoneally with $\alpha$ GalCer. Analysis of serum cytokines at $4 \mathrm{~h}$ postinjection revealed significantly reduced levels of IL-2, IL-4, IL-6, IFN $\gamma$, and TNFa in CD4 ${ }^{\text {cre }} ;$ IRE $1 a^{\Delta / \Delta}$ mice compared to littermate controls (Fig. 3a, upper panel). Similarly, significantly fewer cytokine-positive iNKT cells were detected in the spleens of CD $4^{\text {cre }} ; \operatorname{IRE} 1 \alpha^{\Delta / \Delta}$ mice following injection of $\alpha$-GalCer relative to controls (Fig. $3 b$ ), and bulk splenic IRE1 $\alpha$-deficient iNKT cells restimulated in vitro secreted significantly less cytokines than did control iNKT cells (Fig. 3a, lower panel). Subsequent FACS sorting and expansion of splenic iNKT sublineages from control and CD4 ${ }^{\text {cre }} ; \operatorname{IRE} 1 \alpha^{\Delta / \Delta}$ mice revealed that NKT1 and NKT17 cells required IRE1 $\alpha$ for the production of cytokines following TCR restimulation (Fig. $3 \mathrm{c}$ ), as well as for the expression of cytokine mRNAs (Fig. 3d). In contrast, neither NKT2 cells nor polarized conventional CD4 ${ }^{+} \mathrm{T}$ cells showed a requirement for IRE1 $\alpha$ in the expression and translation of cytokine mRNAs (Fig. 3c, d, and Supplementary Fig. 3A-C), suggesting that IRE1a regulates cytokine mRNA expression within the NKT1 and NKT17 sublineages.

Genetic deletion of IRE1a has previously been shown to result in activation of the PERK signaling pathway ${ }^{33}$ which is noteworthy as PERK promotes phosphorylation of eIF2 $\alpha$ thereby preventing cap-dependent translation of many cellular mRNAs. 


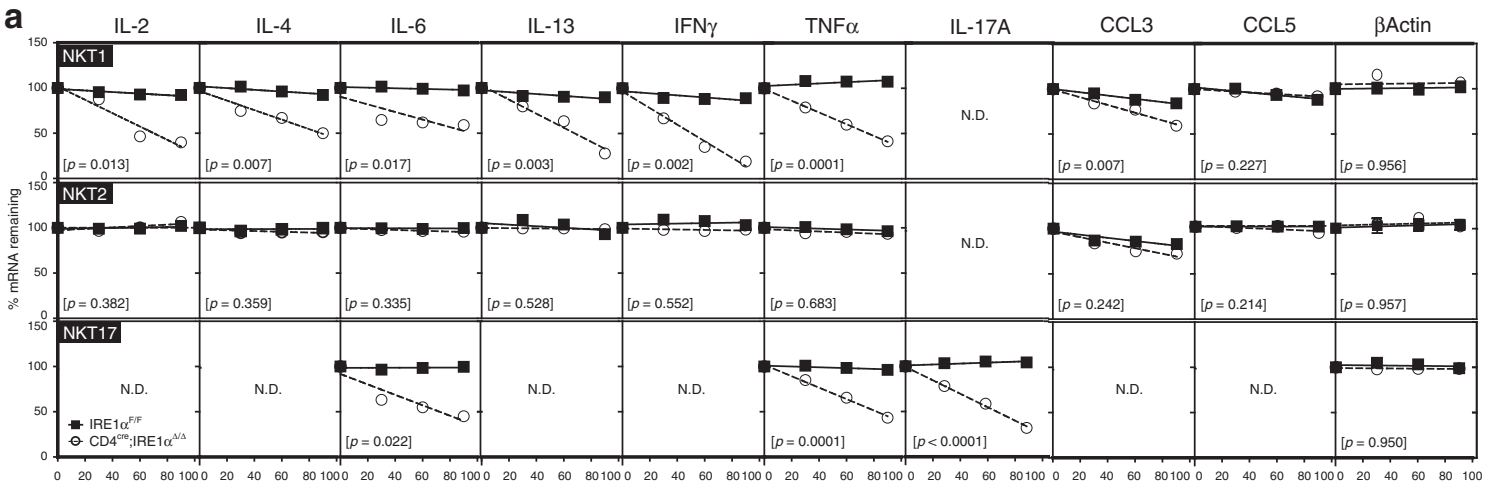

Actinomycin D (min.)

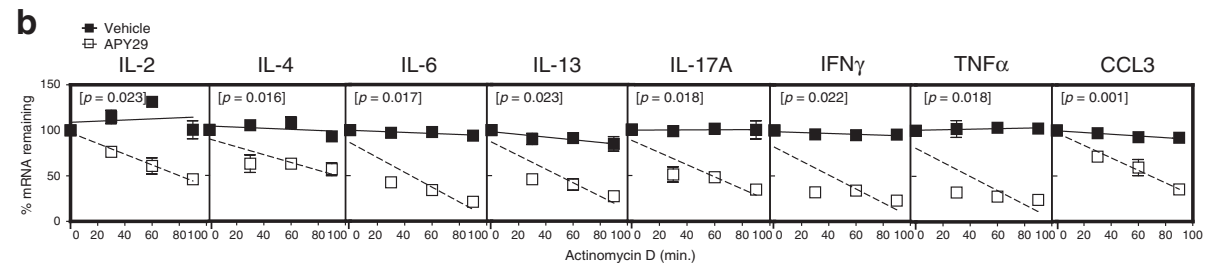

C Vehicle
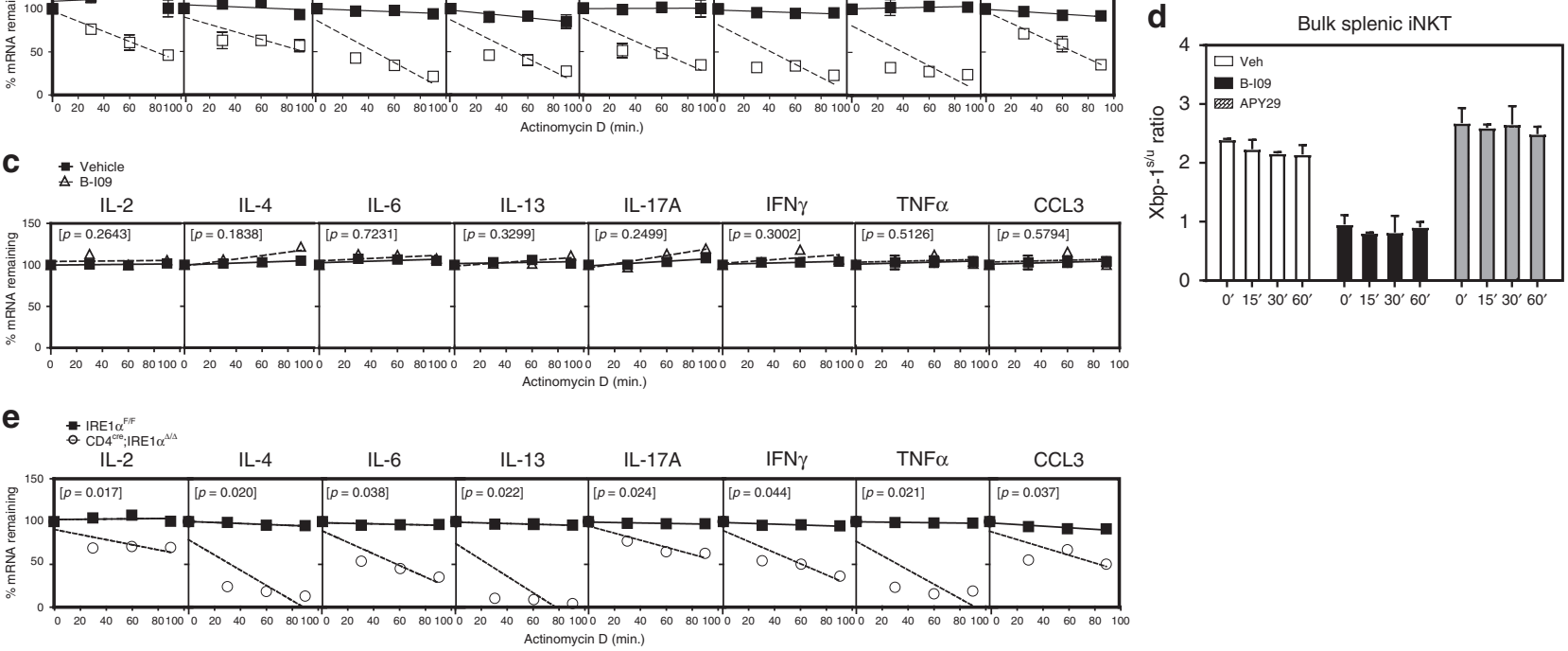

Fig. 4 Reduced cytokine mRNA stability in IRE1 $\alpha$-deficient iNKT cells. a Splenic NKT1, 2 and 17 cells were isolated from control $(n=4)$ and CD4cre;IRE1 $\alpha^{\Delta / \Delta}$ $(n=4)$ mice, expanded and restimulated with anti-CD3/CD28 for $3 \mathrm{~h}$ prior to addition of actinomycin D. mRNA decay rates were determined by linear regression analysis. Data represent three independent experiments pooled. $\mathbf{b}-\mathbf{d}$ Bulk splenic wild-type iNKT cells were expanded in vitro, restimulated with anti-CD3/CD28 for $3 \mathrm{~h}$ in the presence of APY29 and B-109, and then treated with actinomycin D. mRNA decay rates were determined as above. Data represent two independent experiments pooled. e Purified bulk splenic iNKT cells from control $(n=6)$ and $\operatorname{CD} 4^{\text {cre }} ;$ IRE $1 \alpha^{\Delta / \Delta}(n=6)$ mice were restimulated ex vivo with $\alpha-C D 3 / C D 28$ for $3 \mathrm{~h}$, prior to addition of actinomycin $\mathrm{D}$. Data represent two independent experiments pooled. Error bars show the mean \pm s.e.m. $p<0.05$ determined by linear regression analysis and ANOVA, n.d. not detected

Reduced cytokine levels in IRE1a-deficient iNKT cells may therefore have been a consequence of enhanced PERK-eIF2 $\alpha$ activity. To control for this, we sorted and expanded bulk splenic iNKT cells from control and CD4 ${ }^{\text {cre }} ; \mathrm{IRE} 1 \alpha^{\Delta / \Delta}$ mice and restimulated them in vitro with anti-CD3/CD28 (Fig. 3e). Importantly, both control and IRE1a-deficient iNKT cells expressed identical intracellular levels of eIF2 $\alpha$ and phosphorylated eIF2 $\alpha$ (Fig. 3e) following TCR-mediated restimulation, confirming that reduced cytokine levels in IRE1 $\alpha$-deficient iNKT cells is not a consequence of a general inhibition in mRNA translation.

Cytokine mRNA stability within NKT1 and 17 requires IRE1a. To examine whether IRE1a serves to regulate stabilization of cytokine mRNAs within activated iNKT sublineages, we FACS sorted NKT1, 2 and 17 sublineages from the spleens of control and IRE1a-deficient and expanded them in vitro as previously described $^{34}$. Following expansion, resting iNKT sublineages were restimulated with anti-CD3/CD28 and then treated with actinomycin D to inhibit mRNA transcription. Here, the rate of mRNA decay is expressed as the percentage mRNA remaining after the zero timepoint of actinomycin D addition. As shown in Fig. 4a, linear regression analysis of the percentage change in cytokine mRNAs present in control and IRE1a-deficient iNKT cells following addition of actinomycin $\mathrm{D}$ revealed a significant difference in the rate of cytokine mRNA decay within IRE1 $\alpha$-deficient NKT1 and NKT17, but not NKT2 sublineages. It is noteworthy that an elevated mRNA decay rate was also observed for the chemokine CCL3 within NKT1 cells, but not CCL5. Furthermore, we found no significant differences in the decay rates for several mRNAs commonly associated with "housekeeping" functions (e.g. Actb, Fig. 4a), suggesting that IRE1a regulates stability of mRNAs associated with iNKT sublineage effector function. These findings could be reproduced in expanded bulk splenic wild-type iNKT cells treated pharmacologically with the IRE1 $\alpha$ inhibitors APY29 and B-109 (Fig. 4b, c). As observed for IRE1a-deficient iNKT cells, chemical inhibition of the kinase domain of IRE1a with APY29 resulted in significant mRNA decay rates for effector cytokines and chemokines relative to vehicle controls (Fig. 4b). Interestingly, chemical inhibition of the RNase domain of IRE1a with B-I09 does not affect the mRNA decay rates for effector cytokines and chemokines relative to vehicle controls (Fig. 4c). Importantly, decreased cytokine mRNA stability was also 
observed in IRE1 $\alpha$-deficient iNKT cells stimulated ex vivo relative to controls (Fig. 4e). However, the effects of APY29 and B-I09 on XBP1 splicing were maintained as described earlier ${ }^{35,36}$ (Fig. 4d). Thus, effector mRNAs within activated NKT1 and 17 sublineages are regulated by the kinase domain of IRE1 $\alpha$.

An IRE1a-p38 MAPK pathway regulates cytokine mRNA stability. During ER stress, oligomerization of the luminal domain of IRE1a is associated with increased serine-threonine kinase activity within the cytosolic domain of the protein ${ }^{9}$. The kinase activity of IRE1 $a$ has been shown to be important in recruiting a signaling complex consisting of TRAF2 14 or TRAF6 37 and activation of the stress protein kinases c-Jun amino-terminal kinase (JNK) and p38 mitogen-activated protein kinase (MAPK), respectively $14,38,39$. Both JNK and p38 MAPK have been shown to regulate gene expression within the $\mathrm{T}$-cell compartment by regulating cytokine mRNA stability ${ }^{40,41}$, suggesting that IRE1 $\alpha$ might function within activated iNKT cells in a similar manner.

We next examined whether IRE1 $\alpha$ regulates activation of the JNK or p38 MAPK signaling pathways in TCR restimulated iNKT cells. For these experiments, control and IRE1 $\alpha$-deficient iNKT cells were FACS sorted from the spleens of IRE $1 \alpha^{\mathrm{F} / \mathrm{F}}$ and CD4 ${ }^{\text {cre }} ;$ IRE $1 a^{\Delta / \Delta}$ mice and expanded in vitro. Resting control and IRE1 $\alpha$-deficient iNKT cells were then restimulated with antiCD3/CD28 and analyzed for intracellular expression of JNK, phosphorylated JNK (p-JNK), p38, and p-p38 by FACS. As shown in Fig. 5a, b, JNK and p38 MAPK protein kinases become phosphorylated in wild-type iNKT cells within the first $10 \mathrm{~min}$ following TCR restimulation. In contrast, IRE1a-deficient iNKT cells show a delayed phosphorylation kinetic for JNK (Fig. 5a), whereas phosphorylation of p38 is almost completely abolished when compared to control iNKT cells (Fig. 5b). To examine the functional relevance of JNK or p38 phosphorylation on cytokine mRNA stability in iNKT cells post TCR ligation, we restimulated wild-type iNKT cells in the presence of the JNK inhibitor BI-78D3 ${ }^{42}$, or the p38 MAPK inhibitor SB20358043, prior to actinomycin D addition. Here, incubation of restimulated iNKT cells with the JNK inhibitor BI-78D3 had a negligible effect on cytokine mRNA stability when compared to vehicle controls (Fig. 5c) whereas p38 MAPK activity was found to be essential for maintaining stabilized mRNA transcripts in iNKT cells following TCR ligation (Fig. 5d). We therefore conclude that both JNK and p38 MAPK protein kinases are activated in iNKT cells post TCRligation; however, the regulation of p38 MAPK activity by IRE1 $\alpha$ is needed to maintain cytokine mRNA stability following activation.

IRE1 $\alpha$ activity within iNKT cells regulates oxazolone colitis. The above data show that IRE1a is an important regulator of TCR-dependent cytokine production by iNKT cells. To evaluate whether these findings were relevant to the development of inflammation in a murine model of disease, we induced experimental colitis in wild-type IRE1 $\alpha^{\mathrm{F} / \mathrm{F}}$ and CD4 $4^{\mathrm{cre}} ; \mathrm{IRE} 1 \alpha^{\Delta / \Delta}$ mice using oxazolone. Oxazolone is a haptenizing agent that induces Th2-driven mucosal inflammation in a manner dependent on CD1d and iNKT cells ${ }^{44,45}$. As shown in Fig. 6a, wild-type IRE1 $\alpha^{\mathrm{F} /}$ $\mathrm{F}$ mice that were rechallenged intrarectally with $1 \%$ oxazolone lost significantly more weight than did the oxazolone-treated CD4 ${ }^{\text {cre; }}$; IRE $1 a^{\Delta / \Delta}$ mice or ethanol-treated controls (Fig. 6a). Weight loss within rechallenged wild-type IRE $1 \alpha^{\mathrm{F} / \mathrm{F}}$ mice was also associated with significantly reduced colon length (Fig. 6b), as well as increased myeloperoxidase activity within distal colon samples when compared to oxazolone-treated CD4 ${ }^{\text {cre }}$ IRE $1 \alpha^{\Delta / \Delta}$ littermate samples (Fig. 6c). In line with these findings, histopathology scores were elevated in oxazolone-treated wild-type IRE1 $\mathrm{a}^{\mathrm{F} / \mathrm{F}}$ mice compared with $\mathrm{CD} 44^{\mathrm{cre}} ; \mathrm{IRE} 1 \alpha^{\Delta / \Delta}$ mice (Fig. 61). Here, colons of oxazolone-treated wild-type $\mathrm{IRE} 1 \alpha^{\mathrm{F} / \mathrm{F}}$ mice exhibited infiltration of inflammatory cells into the mucosa and lamina propria, as well as areas of mucosal erosion (Fig. 6h, i), that were not observed in oxazolone-treated CD $4^{\text {cre } ; I R E ~} 1 \alpha^{\Delta / \Delta}$ littermates or ethanol-treated control mice (Fig. $6 \mathrm{~d}-\mathrm{k}$ ). These results therefore show that genetic deletion of IRE1 a within iNKT cells protects mice from mucosal inflammation in the oxazolone colitis mouse model.

\section{Discussion}

We propose that IRE1a, a UPR sensor, links key cellular processes involved in the regulation of cytokine production by activated iNKT cells. Results presented here show that TCR-mediated stimulation of the NKT1 and NKT17 sublineages results in autophosphorylation of IRE1a and subsequent splicing of XBP1, a UPR-specific transcription factor, that is involved in remodeling of the ER and preparing cells for enhanced cytokine secretion. Activation of the kinase domain of IRE1a promotes downstream activation of the p38 MAPK-signaling pathway which, in turn, regulates cytokine mRNA stability within the NKT1 and NKT17 sublineages. These findings provide a mechanistic link between the induction of ER stress in iNKT cells and the regulation of organ-specific inflammation in mice, as shown here using a murine model of intestinal inflammation.

Induction of ER chaperones and activation of the IRE1adependent UPR signaling arm in iNKT cells after TCR ligation is consistent with previous reports showing induction of UPR in TCR-stimulated $\mathrm{T}$ cells ${ }^{31,46}$. These studies did however not discriminate between $\mathrm{CD}^{+}{ }^{+}$helper $\mathrm{T}$ cells and $\mathrm{CD} 4^{+}$iNKT cells when analyzing UPR activity within bulk $\mathrm{CD} 4^{+} \mathrm{T}$-cell lineages. FlowSOM analysis of ERA1-transgenic mice performed in this study clearly shows highest expression of constitutively active IRE1a RNase within the iNKT cell lineage, particularly within peripheral iNKT cells, with little to no IRE1a RNase activity detected within the $\mathrm{CD}^{+}$or $\mathrm{CD}^{+}$T-cell compartments in steady-state mice. Furthermore, an analysis of TCR-stimulated $\mathrm{TH}$-polarized $\mathrm{CD} 4^{+} \mathrm{T}$ cells in vitro showed no requirement for IREla in regulating cytokine mRNA expression or stability, arguing against a role for IRE1 $\alpha$-induced cytokine production in conventional $\mathrm{CD}^{+}{ }^{+} \mathrm{T}$-cell lineages. Although induction of an ER stress-response phenotype may be associated with priming of $\mathrm{CD}^{+}$and $\mathrm{CD}^{+}{ }^{+}$-cell lineages ${ }^{21,22}$, constitutive IRE1a RNase activity within peripheral NKT1 and NKT17 sublineages may be comparable with a cellular phenotype observed within specialized secretory cells. For example, terminal differentiation of mature B cells into plasma cells requires both IRE1 $\alpha$ and XBP1 5,30 , and the upregulation of genes encoding secretory pathway components in plasma cells is coordinated by XBP1 ${ }^{12}$. Similarly, an IRE1-XBP1 signaling axis is needed for development and differentiation of salivary gland acinar cells ${ }^{47}$, pancreatic beta cells ${ }^{48}$, and hepatocytes $^{49}$. Although we found no requirement for IRE1a during iNKT sublineage specification and development, we propose that IRE1 $a$-dependent signaling promotes NKT1 and NKT17 sublineage effector function in a manner analogous to the role of IRE1-XBP1 signaling during immunoglobulin production in plasma cells ${ }^{5,30}$. Similarly, TCR-dependent induction of ERassociated protein chaperones in NKT1 and NKT17 cells would facilitate increased cytokine protein folding and secretion both in vitro and in vivo. The unexpected finding that IRE1 $\alpha$ regulates cytokine mRNA stability within restimulated NKT1 and NKT17 sublineages is, to our knowledge, the first dataset that describes a mechanistic link between the maintenance of preformed cytokine mRNAs within iNKT cells and their ability to rapidly produce cytokines following activation ${ }^{3}$. Although transcriptional regulation of Il4 mRNA within iNKTs has been previously associated with chromatin accessibility of the Il4 locus ${ }^{2}$, our data show that IRE1 $\alpha$-mediated regulation of several cytokine 

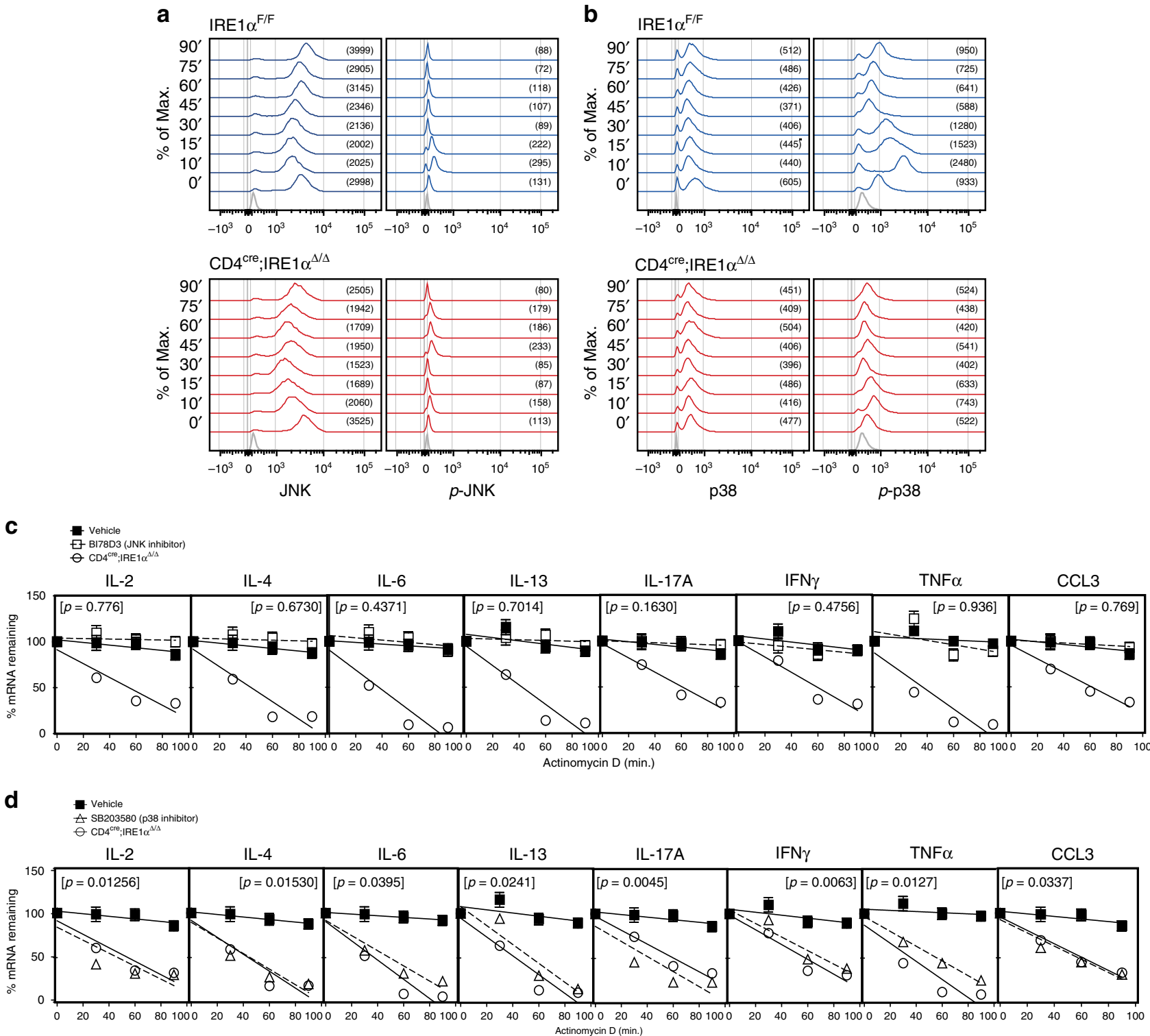

Fig. 5 p38 MAPK regulates cytokine mRNA stability in iNKT cells. a, b Bulk splenic iNKT cells from IRE1 $\alpha^{\mathrm{F} / \mathrm{F}}(n=4)$ and CD4cre;IRE1 $\alpha^{\Delta / \Delta}(n=4)$ mice were expanded and restimulated with anti-CD3/CD28 from 0 to 90 min. Histograms represent intracellular expression of JNK, phospho-JNK, p38 and phospho-p38 in control and IRE1 $\alpha$-deficient iNKT cells following TCR restimulation, respectively. Isotype controls (gray) are shown at the bottom of the histogram overlays. Numbers in brackets represent MFI for JNK, p-JNK, p38 and p-p38 expression within FACS-gated iNKT cells. Histograms are representative of three independent experiments. c, $\mathbf{d}$ Purified bulk splenic wild-type iNKT cells were restimulated ex vivo with anti-CD3/CD28 for $3 \mathrm{~h}$ in the presence of the JNK inhibitor BI-78D3 (c) or the p38 inhibitor SB203580 (d), prior to addition of actinomycin D. Resting iNKT cells were then restimulated with anti-CD3/CD28 for $3 \mathrm{~h}$ and then treated with actinomycin D. mRNA decay rates were determined by linear regression analysis. Data represents three independent experiments pooled. Error bars show the mean \pm s.e.m. $p<0.05$ determined by linear regression analysis and ANOVA

mRNAs is an essential mechanism controlling iNKT cell effector function. Importantly, incubation of iNKT cells with the kinase inhibitor APY29 is associated with decreased cytokine mRNA stability for in vitro expanded restimulated iNKT cells. However, decreased cytokine mRNA stability within iNKT cells was not affected in the presence of RNase domain inhibitor B-I09 (Fig. 4d). These findings are in agreement with a role for the kinase domain of IRE1a in the downstream activation of protein kinases such as $\mathrm{JNK}^{14}$. It remains to be determined how activation of IRE1 $\alpha$ induces phosphorylation of p38 MAPK within iNKT cells; however, we have been able to formally exclude a role for either TRAF2 or TRAF6 in this signaling pathway (Supplementary Fig. 4A).
Our findings are in line with a previous report describing a role for MAPK kinase (MKK) 3, an upstream activator of the p38 MAPK pathway, in regulating cytokine production by iNKT cells ${ }^{50}$. MKK3, p38, and the downstream kinase MAPKactivated protein kinase (MAP-KAPK)-2 have been previously associated with the stabilization of inflammatory mRNAs ${ }^{51}$. In this context, a common characteristic of inflammatory mRNAs is the presence of AU-rich sequences in their 3' untranslated regions. AU-rich elements (ARE) can act as potent mRNA destabilizing sequences as they can target mRNA for rapid deadenylation in vivo as well as promote $3^{\prime}-5^{\prime}$ exonuclease decay $^{52}$. It has been proposed that $\mathrm{p} 38$-mediated stabilization of inflammatory mRNAs is facilitated by a class of ARE-binding 


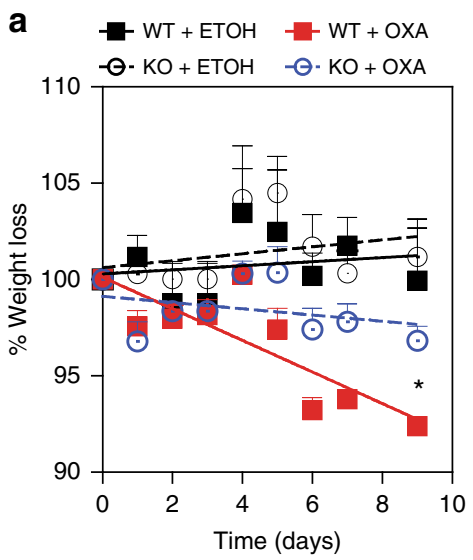

b

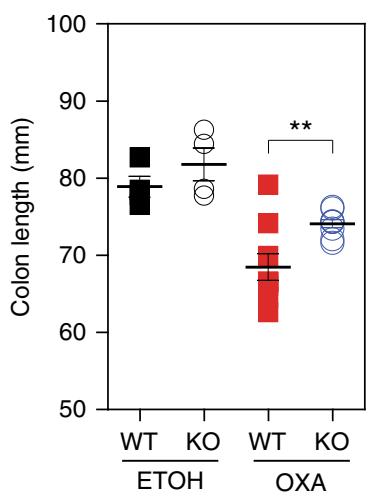

C

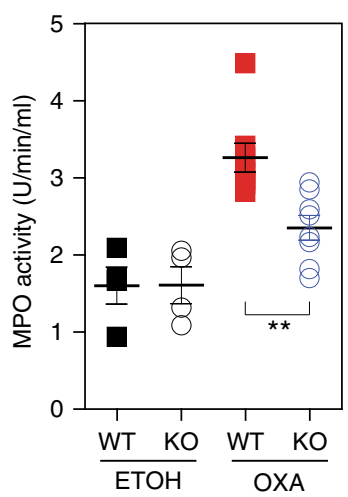

I

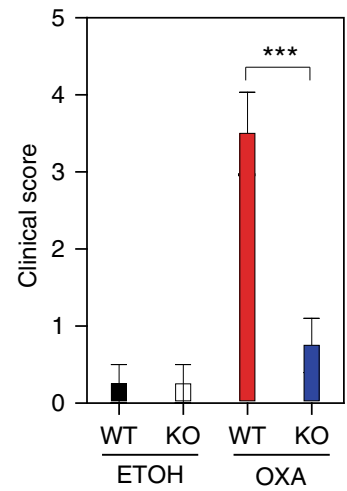

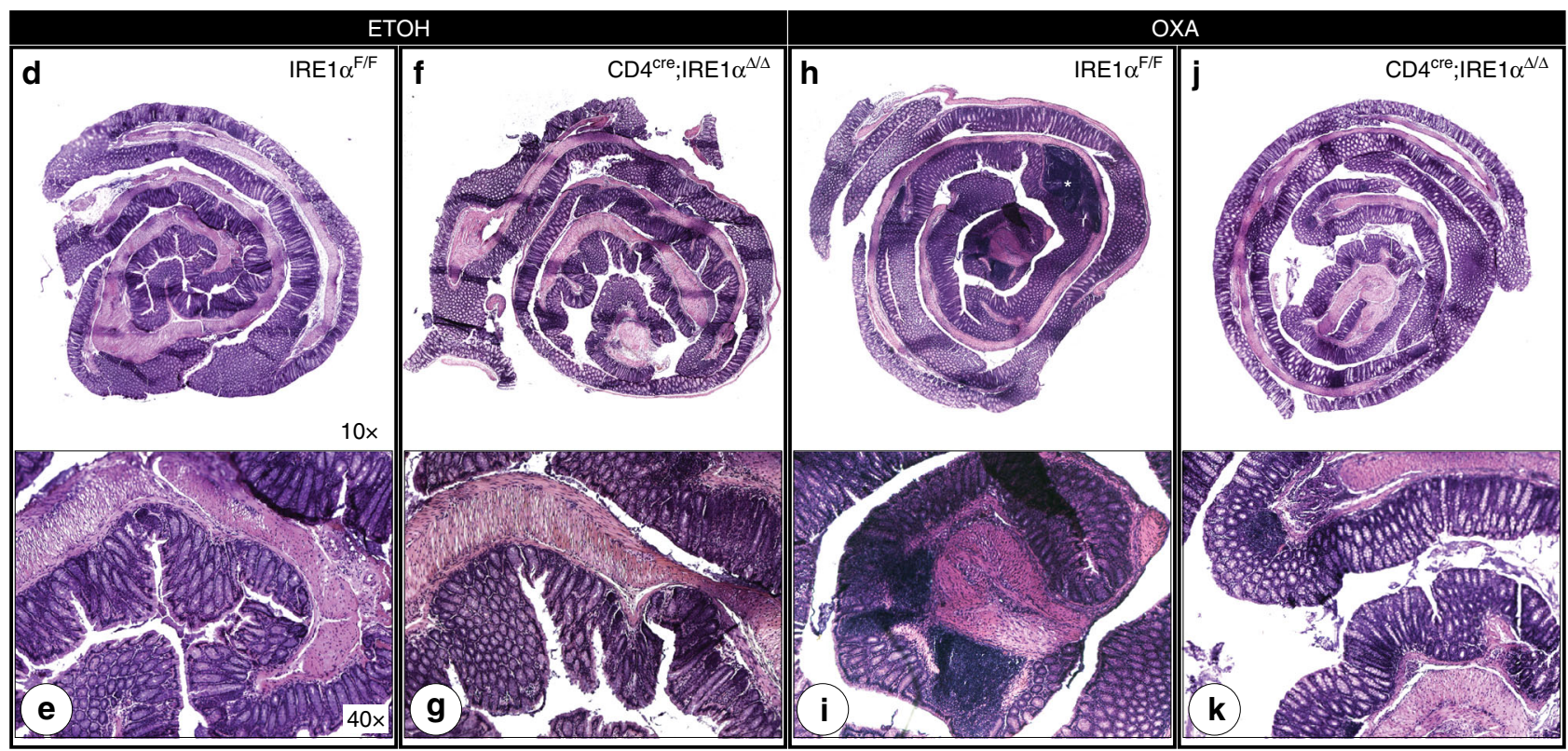

Fig. 6 Deletion of IRE1 $\alpha$ within iNKT cells protects mice from oxazolone colitis. IRE1 $\alpha^{\mathrm{F} / \mathrm{F}}$ control $(n=10)$ and $\mathrm{CD} 4{ }^{\mathrm{cre}} ; \mathrm{IRE} 1 \alpha^{\Delta / \Delta}(n=10)$ mice were presensitized with either ethanol (ETOH) or $3 \%$ oxazolone (OXA) and then challenged intrarectally with either ethanol or $1 \%$ oxazolone 7 days after intrarectal challenge. Weight loss (a), colon length (b), MPO activity (c) and clinical score (I) were subsequently evaluated for each group after the intrarectal challenge. Data represent mean values obtained from two independent experiments. $\mathbf{d}, \mathbf{f}, \mathbf{h}, \mathbf{j}$ Photomicrographs $(\times 10)$ of hematoxylin and eosin $(H \& E)$-stained sections of whole intestine removed from ethanol or oxazolone-treated control $(\mathbf{d}, \mathbf{h})$ and $C D 4$ cre; IRE1 $\alpha^{\Delta / \Delta}(\mathbf{f}, \mathbf{j})$ mice 5 days after intrarectal challenge. $\mathbf{e}, \mathbf{g}, \mathbf{i}, \mathbf{k}$ Photomicrographs $(\times 40)$ represent boxed distal regions of $10 \times \mathrm{H \& E}$-stained sections representative for each group. Asterisk indicates areas of mucosal erosion. Error bars show the mean \pm s.e.m. Mixed model analysis was performed to assess differences in weight loss and ${ }^{\star} p<0.05,{ }^{\star \star} p<0.01,{ }^{\star \star \star} p<0.001$ determined by Mann-Whitney $U$ test

proteins (AREBP), such as TIA-1, which are functionally altered following activation of the p38 MAPK signaling pathway ${ }^{53}$. It remains to be determined whether IRE1a-p38-mediated stabilization of cytokine mRNAs within iNKT cells requires downstream modulation of AREBP function; however, it is interesting to note that TIA-1 has previously been shown to modulate IL-4 production within $\mathrm{CD} 4^{+} \mathrm{T}$ cells ${ }^{22}$.

Finally, the finding that $C D 4^{\text {cre }} ;$ IRE $1 a^{\Delta / \Delta}$ mice are protected from oxazolone colitis suggests that IRE1 $\alpha$-dependent signaling contributes to iNKT cell effector function in vivo as well. These results are significant as it suggests that IRE1 $\alpha$-mediated stabilization of cytokine mRNAs may be a general intracellular signaling cascade required for modulating iNKT cell effector function in vivo. Currently, a range of inflammatory, allergic and autoimmune diseases are believed to be modulated by cytokines secreted by iNKT cells in mouse and human. Although we were able to show that inhibition of IRE1 $\alpha$ kinase function using
APY29 inhibited cytokine mRNA stability in cultured iNKT cells, in vivo administration of APY29 to target iNKT cell effector function may have unwanted off-target side-effects such as inhibition of exocrine gland and liver function ${ }^{47,49}$. We therefore propose that a more detailed understanding of the mechanism by which IRE1 $\alpha$ regulates cytokine production in iNKT cells may yield novel insights into signaling pathways that can be pharmacologically targeted to either inhibit or augment iNKT celldriven disease.

\section{Methods}

Transgenic mice. $\mathrm{Tg}\left(\mathrm{CAG}-\mathrm{XBP} 1^{\star} / \text { Venus) }\right)^{\# \text { Miur }}$ (ERAI-transgenic) mice have been previously described ${ }^{23}$. T-cell-specific IRE1 1 -deficient mice (CD4 ${ }^{\text {cre }} ;$ IRE1 $1 \alpha^{\Delta / \Delta}$ ) were generated by intercrossing mice carrying a LoxP flanked IRE1 $\alpha$ allele ${ }^{33}$ with CD4-cre transgenic mice ${ }^{34}$. These transgenic mice were intercrossed with CXCR69fp mice for intravital imaging of iNKT cells as previously described ${ }^{32}$ All mice were housed and bred according to the guidelines of the Ghent University 
vivarium. All animal procedures were approved by the Institutional Animal Care and Ethics Committee.

Flow cytometry and antibodies. Cells were analyzed on FACSCantoII (BD Biosciences) and FlowJo software (Tristar), and sorted on FACS Aria III (BD Biosciences). Antibodies used were CD122- PerCP-eFluor710 (TM-B1/46-1222-82/ 1:200), CD19-eFluor 450 (eBio1D3/48-0193-82/1:300), CD24-FITC (M1-69/110242-82/1:250), CD25-PE (PC61.5/12-0251-82/1:400), CD27-APC (LG.7F9/470271-82/1:150), CD3E-V500 (500A2/560771/1:100/BD Biosciences), CD4-FITC/ APC-eFluor780 (RM4-5/11-0042-82/17-00471-83/1:280), CD44-FITC/APCeFluor780 (IM7/11-0441-85/25-0441-U100/1:275), CD62L-PE-Cy7 (MEL-14/600621-50U/1:600/TONBO), NK1.1-PE-Cy7 (PK136/25-5941-82/1:400), CD8 $\alpha-$ V500 (53-6.7/560776/1:300/ BD Biosciences), $\beta$ TCR-APC-eFluor780 (H57-597/475961-82/1:400), $\gamma \delta$ TCR-PerCP-eFluor710 (eBioGL3/46-5711-82/1:250), IL2-PE-

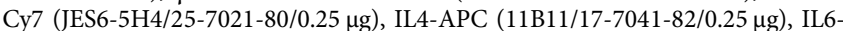

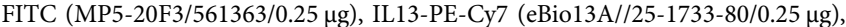
IFN $\gamma$-FITC (XMG1.2/11-7311-81/0.25 $\mu$ g), TNFa-APC (MP6-XT22/17-7321-81/ $0.25 \mu \mathrm{g}$ ), T-bet-PE (eBio4B10/12-5825-82/0.25 $\mu \mathrm{g}$ ), Gata-3-AlexaFluor488 (TWAJ/ 14-9966-82/0.25 $\mu \mathrm{g}$ ), ROR $\gamma \mathrm{t}-\mathrm{PE}$ (B2D/12-6981-80/0.25 $\mu \mathrm{g}$ ), PLZF-AlexaFluor488 (Mags.21F7/53-9320-82/0.25 $\mu \mathrm{g}$ ) (all other antibodies are from Invitrogen/ eBioscience). p38 $\alpha / \beta$ (A-12), JNK (D-2), $\beta$-Actin (from Santa Cruz Biotechnology, p-p38 MAPK-AlexaFluor 488 (28B10), p-JNK-AlexaFluor 647 (G9), IRE-1 $\alpha$ (14C10/3294/1:1000), and EIF2 $\alpha$ (9722/1:1000) from Cell Signaling). $\alpha$-GalCerloaded CD1d tetramers (1:400) and MR1-5-OP-RU-APC (NIH/1:800). iNKT cells were stained at $4^{\circ} \mathrm{C}$ using $\alpha$-GalCer-loaded CD1d tetramers. MAIT cells were stained at room temperature using MR1-5-OP-RU tetramer ${ }^{+}$provided by $\mathrm{NIH}$ tetramer core facility, USA. Stainings for intracellular proteins were performed using the FoxP3/Transcription Factor staining buffer set (eBioscience) for iNKT cell transcription factors or methanol for protein kinases according to the manufacturers' recommendations. T lymphocyte subsets are defined as $\mathrm{DN}\left(\mathrm{CD} 3 \varepsilon^{-} \mathrm{CD} 4\right.$ $\left.{ }^{-} \mathrm{CD} 8{ }^{-}\right)$; DP $\left(\mathrm{CD} 3 \varepsilon^{-} \mathrm{CD} 4{ }^{+} \mathrm{CD} 8{ }^{+}\right)$; $\mathrm{CD}^{+}{ }^{+} \mathrm{T}\left(\mathrm{CD} 4{ }^{+} \mathrm{CD} 8^{-} \mathrm{CD} 1 \mathrm{~d}-\mathrm{aGC}^{-} \mathrm{TCR} \beta^{+}\right)$; $\mathrm{CD}^{+} \mathrm{T}\left(\mathrm{CD} 4^{-} \mathrm{CD} 8^{+} \mathrm{CD} 1 \mathrm{~d}-\alpha \mathrm{GCC}^{-} \mathrm{TCR}^{+}\right)$; iNKT $\left(\mathrm{TCR} \beta^{+} \mathrm{CD} 1 \mathrm{~d}-\alpha \mathrm{GC}^{+}\right)$; NKTLike $\left(\right.$ TCR $\beta^{+}$CD1d- $\left.\alpha \mathrm{GC}^{-} \mathrm{NK} 1.1^{+}\right)$, MAIT (MR1-5-OP-RU tetramer ${ }^{+}$TCR $^{+}$) and $\gamma \delta^{+} \mathrm{T}\left(\mathrm{TCR} \gamma \delta^{+} \mathrm{TCR} \beta^{-}\right)$. TCR $\beta^{+} \mathrm{CD} 1 \mathrm{~d}-\alpha \mathrm{GC}^{+} \mathrm{NKT}$ sublineages are defined as NKT1 $\left(\mathrm{CD} 27^{+/-} \mathrm{IL}-2 \mathrm{R} \beta^{+}\right)$, NKT2 $\left(\mathrm{CD} 27^{+} \mathrm{IL}-2 \mathrm{R} \beta^{-}\right)$, and NKT17 $\left(\mathrm{CD} 27^{-} \mathrm{IL}-2 \mathrm{R} \beta^{-}\right)$.

FlowSOM analysis. FlowSOM analysis was performed as described previously ${ }^{24}$ Briefly, T-cell subsets were manually gated and the data for all the selected cells were aggregated per tissue. FlowSOM analysis used intensity measurements for NK1.1, CD4, $\alpha$-GalCer-loaded CD1d tetramer, $\beta$ TCR, $\gamma \delta$ TCRand CD8 $\alpha$ to group the cells into 100 nodes where node size indicates the mean percentage of cells assigned to the nodes. For analysis of Venus $\mathrm{s}^{\mathrm{FP}}$ expression, the median Venus $\mathrm{FP}$ expression was computed for each node per sample. The final color value assigned to the node corresponds to the difference between the mean of the values obtained for ERAI-transgenic and wild-type mice, respectively.

Cell suspension preparations. Single cell suspensions from the thymus were resuspended in phosphate-buffered saline (PBS) containing $1 \mathrm{mM}$ ethylenediaminetetraacetic acid (EDTA) and $0.5 \%$ bovine serum albumin (BSA) while spleen and liver suspensions were layered over Ficoll or 33\% Percoll gradients, respectively. Peripheral blood mononuclear cells (MNCs) were isolated by cardiac puncture in $20 \mathrm{U} / \mathrm{ml}$ PBS/heparin. iNKT thymocytes were enriched for using mouse CD8Dynabeads (Invitrogen) and resuspended in $2 \mathrm{ml}$ PBS containing $1 \mathrm{mM}$ EDTA and $0.5 \% \mathrm{BSA}$.

iNKT cell isolation, expansion, and restimulation. iNKT cells were FACS sorted from CD5-enriched MNCs isolated from the spleens or livers of pooled C57Bl/6, IRE $1 \alpha^{\mathrm{F} / \mathrm{F}}$ or $\mathrm{CD} 4^{\mathrm{cre}} ; \mathrm{IRE} 1 \alpha^{\Delta / \Delta}$ mice as described earlier ${ }^{54}$. Briefly, $\alpha$-GalCer/CD1d tetramer ${ }^{+}$TCR $^{+}{ }^{+}$iNKT cells present within the lymphocyte were gated after eliminating cell doublets, dead cells, $\mathrm{CD} 19^{+}$and $\gamma \delta \mathrm{T}$ lymphocytes from the analysis by plotting FSC-H versus FCS-W, DAPI, CD19 (eFluor450), $\gamma \delta$ TCR (PerCpCy5.5) versus FSC-A, respectively (Supplementary Fig. 5). For ex vivo stimulation experiments, FACS-sorted iNKT cells were allowed to rest for $3 \mathrm{~h}$ after which $0.5 \times$ $10^{6}$ iNKT cells were resuspended in complete RPMI 1640 medium ( $10 \%$ heat inactivated FCS, $100 \mathrm{U} / \mathrm{ml}$ penicillin/streptomycin, $2 \mathrm{mM}$ glutamine, $0.1 \mathrm{mM}$ nonessential amino acids, $5.5 \times 10^{2} \mu \mathrm{M} \mu$-ME, all from GIBCO) and stimulated

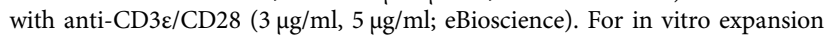
experiments, sorted splenic bulk iNKT or NKT sublineages were resuspended in complete RPMI 1640 medium containing murine IL-2 $(10 \mathrm{ng} / \mathrm{ml})$, IL-12 $(1 \mathrm{ng} / \mathrm{ml})$, and soluble anti-CD28 $(1 \mu \mathrm{g} / \mathrm{ml}$; all from eBioscience) and stimulated with platebound anti-CD3e $(3 \mu \mathrm{g} / \mathrm{ml})$ for 2 days. iNKT cells were then rested for 2 days and resuspended in complete medium containing murine IL-7 (2 U/ml; eBioscience) for 4 days. iNKT cells were then restimulated with plate-bound $\alpha$-CD3 $\varepsilon(3 \mu \mathrm{g} / \mathrm{ml})$ for a further 3 days and subsequently expanded for an additional 10 days in the presence of IL-7 and plate-bound anti-CD3 3 , as described above. For restimulation experiments, $1 \times 10^{6}$ iNKT cells were resuspended in complete RPMI 1640 medium (10\% heat inactivated fetal calf serum (FCS), $100 \mathrm{U} / \mathrm{ml}$ penicillin/streptomycin, $2 \mathrm{mM}$ glutamine, $0.1 \mathrm{mM}$ nonessential amino acids, $5.5 \times 10^{2} \mu \mathrm{M} \mu$-ME, all from
GIBCO) and stimulated with either PMA/Ionomycin $(1 \mu \mathrm{M} / 200 \mathrm{ng} / \mathrm{ml}$, SigmaAldrich), recombinant murine IL-12p70 $(0.1 \mu \mathrm{g} / \mathrm{ml}$, eBioscience), recombinant murine IFN $\beta$ ( $0.1 \mathrm{mg} / \mathrm{ml}$, eBioscience), LPS ( $20 \mathrm{ng} / \mathrm{ml}$; Sigma-Aldrich), Poly I:C (10 ng/ml; Sigma-Aldrich), $10 \mu \mathrm{g} / \mathrm{ml}$ murine CD1d (Sino Biological Inc.) loaded

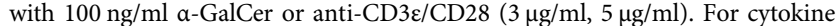
measurements, supernatants were collected after $72 \mathrm{~h}$ of stimulation and measured by ELISA.

Immunoblot analysis and Phos-tag gels. Phosphorylation of IRE1 $\alpha$ was monitored by Phos-tag SDS gels according to the manufacturer's instructions (NARD Institute). Expanded bulk splenic iNKT cells $\left(2 \times 10^{6}\right.$ cells $)$ were stimulated with anti-CD3ع/CD28 $(3 \mu \mathrm{g} / \mathrm{ml}, 5 \mu \mathrm{g} / \mathrm{ml})$ for $0,15,30$ and $60 \mathrm{~min}$. Cells were spun for $10 \mathrm{~min}$ at $400 \times g$ at $4{ }^{\circ} \mathrm{C}$. After centrifugation, the medium was removed and washed with cold PBS. Cells were lysed for $15 \mathrm{~min}$ on ice in E1A buffer (1\% NP40, $20 \mathrm{mM}$ HEPES, pH 7.9, $250 \mathrm{mM} \mathrm{NaCl}, 1 \mathrm{mM}$ EDTA, and protease and phosphatase inhibitors). Insoluble material was discarded by cold centrifugation, and a fixed amount of lysate was mixed with sample buffer before separation by sodium dodecyl sulfate-polyacrylamide gel electrophoresis (SDS-PAGE). Samples were separated using 6\% SDS-PAGE containing $50 \mu \mathrm{M}$ Phos-tag (NARD Institute) and $50 \mu \mathrm{M} \mathrm{MnCl}_{2}$. Gels were soaked in $1 \mathrm{mM}$ EDTA before transfer for $10 \mathrm{~min}$ and transferred onto $0.45 \mu \mathrm{M}$ polyvinyldifluoride membranes (Millipore). After transfer to a membrane, proteins were visualized by enhanced chemiluminescence kit (Thermo scientific).

Polarization and restimulation of naïve $\mathbf{C D 4}{ }^{+} \mathbf{T}$ cells. Naïve $\mathrm{CD} 4^{+} \mathrm{T}$ cells $\left(\mathrm{CD} 4{ }^{+} \mathrm{TCR} \beta^{+} \mathrm{CD} 1 \mathrm{~d}-\mathrm{\alpha GC}{ }^{-} \mathrm{NK} 1.1^{-} \mathrm{CD} 44^{-} \mathrm{CD} 62 \mathrm{~L}^{\text {hi }}\right)$ were $\mathrm{FACS}$ sorted from the pooled spleens of IRE $1 \alpha^{\mathrm{F} / \mathrm{F}}(n=5)$ and $\mathrm{CD} 4^{\mathrm{cre}} ; \operatorname{IRE} 1 \alpha^{\Delta / \Delta}$ mice $(n=5)$, resuspended in complete RPMI 1640 media containing polarizing cytokines and plated at $1 \times 10^{5}$

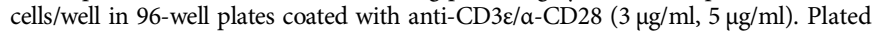
$\mathrm{CD} 4^{+} \mathrm{T}$ cells were differentiated under TH1-polarizing conditions using recombinant murine IL-12 (10 ng/ml, eBioscience), recombinant murine IL-2 $(10 \mathrm{ng} / \mathrm{ml}$, eBioscience), and anti-IL-4 (10 $\mu \mathrm{g} / \mathrm{ml}$, eBioscience); TH2-polarizing conditions using recombinant murine IL-4 (10 ng/ml, eBioscience), recombinant murine IL-2 $(10 \mathrm{ng} / \mathrm{ml})$ and anti-IFN $\gamma(10 \mu \mathrm{g} / \mathrm{ml}$, eBioscience); and TH17-polarizing conditions using recombinant murine IL-6 (20 ng/ml, eBioscience), recombinant murine IL-23 $(10 \mathrm{ng} / \mathrm{ml}),{ }^{55}$, recombinant murine IL-1 $\beta(10 \mathrm{ng} / \mathrm{ml}$, PSF, VIB $)$, recombinant human TGF 1 ( $2 \mathrm{ng} / \mathrm{ml}$, eBioscience), anti-IL-4 $(10 \mu \mathrm{g} / \mathrm{ml})$, anti-IFN $\gamma(10 \mu \mathrm{g} / \mathrm{ml})$ and anti-IL-2 (10 $\mu \mathrm{g} / \mathrm{ml}$, eBioscience), respectively. Cells were then removed from TCR stimuli after 3 days, resuspended at $1 \times 10^{6} / \mathrm{ml}$ in fresh media and cultured in a new 96-well plate without TCR stimuli for 2 days. $1 \times 10^{6}$ polarized T cells were then resuspended in complete RPMI 1640 medium and restimulated using anti$\mathrm{CD} 3 \varepsilon / \mathrm{CD} 28(3 \mu \mathrm{g} / \mathrm{ml}, 5 \mu \mathrm{g} / \mathrm{ml}$; eBioscience).

In vivo stimulation of iNKT cells. For serum cytokine production, $5 \mu \mathrm{g}$ of $\alpha$ GalCer in $200 \mathrm{ml}$ PBS was injected intraperitoneally. Blood was subsequently collected at by retro-orbital puncture at $4 \mathrm{~h}$ postinjection and assayed for cytokine content by ELISA. For intracellular cytokine measurements, $2 \mu \mathrm{g}$ of $\alpha$-GalCer in $200 \mathrm{ml}$ PBS was injected intraperitoneally and splenic iNKT cells were analyzed $2 \mathrm{~h}$ later by flow cytometry. For intravital imaging, $1 \mu \mathrm{g}$ of $\alpha$-GalCer in $20 \mu \mathrm{l}$ PBS was injected intravenously. For in vivo labeling with BrdU (Sigma-Aldrich), the mice were injected i.p. with $1 \mathrm{mg} \mathrm{BrdU}$ (in PBS), followed by injection of $2 \mu \mathrm{g}$ of $\alpha$ GalCer intraperitoneally. At the same time, BrdU $(1 \mathrm{mg} / \mathrm{ml})$ was placed in the drinking water till the end of the experiment. Five days later, splenic iNKT cells were analyzed for BrdU incorporation using a BrdU flow kit (BD Biosciences) according to the manufacturer's instructions.

Intravital microscopy and image analysis. Multiphoton imaging of iNKT cells in the liver was performed as described before ${ }^{56}$. Briefly, to establish a baseline iNKT cell speed, $2 \mathrm{~h}$ of steady-state images were recorded prior to injection with $\mathrm{a}$ GalCer. Imaging was continued for $2 \mathrm{~h}$ postinjection. Images were analyzed with Imaris (Bitplane) using ImarisTrack to quantify iNKT cell speeds over time. Cell velocities were plotted as a moving average of ten frames for each timepoint. Tracks of individual iNKT cells, normalized to their starting coordinates, were plotted with Matlab 9.1 (MathWorks). The square of the displacement distance over time was shown at steady-state and $1 \mathrm{~h}$ postinjection. Finally, a confinement index was calculated by multiplying cell track straightness by the square root of the track duration, both at steady-state and $1 \mathrm{~h}$ postinjection.

Quantitative real-time RT-PCR. Total RNA was extracted from T lymphocytes analyzed in this study using the miRNeasy Mini kit (QIAGEN, Valencia, CA). cDNA was produced and amplified using the QuantiTect Whole Transcriptome Kit (QIAGEN, Valencia, CA). PCR products were amplified with the Fast Start SYBR Green Master mix (Roche, Basel, Switzerland) and detected with a LightCycler 480 System (Roche, Basel, Switzerland). Samples were normalized using qBasePlus (Biogazelle NV, Belgium) against at least three of the following housekeeping genes: Rpl13a, Atp5b, Eif4b, Cycl, B2m, Ubc, Actb, Gapdh, Sdha or Tubb4a Primer sequences for housekeeping, cytokine, ER chaperone and UPR signature genes are listed in Supplementary Table 1. 
RNA stability assays iNKT and differentiated $\mathrm{CD} 4^{+} \mathrm{T}$-cell subsets were stimulated with $\alpha$-CD3e/CD28 $(3 \mu \mathrm{g} / \mathrm{ml}, 5 \mu \mathrm{g} / \mathrm{ml})$ for $3 \mathrm{~h}$ after which $3 \mu \mathrm{g} / \mathrm{ml}$ of actinomycin D (Sigma-Aldrich) was added. RNA was subsequently isolated from actinomycin D-treated iNKT cells using the miRNeasy Mini kit (QIAGEN, Valencia, CA). Cytokine mRNAs were then normalized against at least three housekeeping genes expressed as the \% mRNA remaining after the zero timepoint of actinomycin $\mathrm{D}$ addition. The slope of the line for $\%$ mRNA remaining between 0 and 90 min post-actinomycin $\mathrm{D}$ addition was determined by linear regression for each group or treatment condition. For inhibitor studies, anti-CD3z/a-CD28stimulated iNKT cells were incubated in the presence of $20 \mu \mathrm{M}$ APY29 (4865, Tocris Bioscience), $20 \mu \mathrm{M}$ B-109 (kindly provided by Andrew's lab), $12.5 \mu \mathrm{M}$ B178D3 (Sigma-Aldrich), $2.5 \mu \mathrm{M}$ SB-203580 (Sigma-Aldrich) or equivalent vehicle controls prior to the addition of actinomycin D.

Induction of oxazolone colitis. Eight-week-old mice were presensitized with 200 $\mu \mathrm{l}$ of a $3 \%(\mathrm{w} / \mathrm{v})$ solution of oxazolone (4-ethoxymethylene-2-phenyl-2-oxazoline5 -one, Sigma-Aldrich) in $100 \%$ ethanol or $100 \%$ ethanol alone (vehicle) on the abdominal skin. Five days later mice were anesthetized with a mixture of ketalar, rompun and PBS and rechallenged intrarectally with $150 \mu \mathrm{l}$ of either $1 \%(\mathrm{w} / \mathrm{v})$ oxazolone in $50 \%$ ethanol or $50 \%$ ethanol alone (vehicle).

Histology: Mice were euthanized 10 days after induction of oxazolone colitis. The colons were subsequently removed and fixed with $4 \%$ formalin (SigmaAldrich). After paraffin embedding $7 \mu \mathrm{m}$ sections were cut and stained with hematoxylin-eosin.

Tissue myeloperoxidase activity. Samples of the mid-to-distal colon (adjacent to the samples used for histology) were rinsed with cold PBS, blotted dry, and immediately frozen in liquid nitrogen for storage at $-80^{\circ} \mathrm{C}$. Myeloperoxidase (MPO) activity was determined using the O-dianisidine method.

Statistical analysis. Statistical testing was performed using the unpaired Student's $t$ test unless otherwise indicated. The Mann-Whitney $U$ test was applied when data were demonstrated to not follow a Gaussian distribution, which is indicated in the respective figures legends. Linear regression analysis and ANOVA were performed for mRNA stability assays. Mixed model analysis was performed to assess differences in weight loss. All $p$ values were two-tailed, and statistical significance was assumed at $p<0.05$. For intravital imaging, linear mixed models for repeated measures were used except for the speed distribution, for which binomial logistic regression was performed.

\section{Data availability}

The data that support the findings in this study are available from the corresponding author upon request.

Received: 9 February 2018 Accepted: 21 November 2018

Published online: 17 December 2018

\section{References}

1. Bendelac, A., Savage, P. B. \& Teyton, L. The biology of NKT cells. Annu. Rev. Immunol. 25, 297-336 (2007).

2. Yagi, R., Tanaka, S., Motomura, Y. \& Kubo, M. Regulation of the Il4 gene is independently controlled by proximal and distal 3 ' enhancers in mast cells and basophils. Mol. Cell. Biol. 27, 8087-8097 (2007).

3. Stetson, D. B. et al. Constitutive cytokine mRNAs mark natural killer (NK) and NK T cells poised for rapid effector function. J. Exp. Med. 198, 1069-1076 (2003).

4. Constantinides, M. G. \& Bendelac, A. Transcriptional regulation of the NKT cell lineage. Curr. Opin. Immunol. 25, 161-167 (2013).

5. Iwakoshi, N. N. et al. Plasma cell differentiation and the unfolded protein response intersect at the transcription factor XBP-1. Nat. Immunol. 4, 321-329 (2003).

6. Van Anken, E. et al. Sequential waves of functionally related proteins are expressed when B cells prepare for antibody secretion. Immunity 18, 243-253 (2003).

7. Ron, D. \& Walter, P. Signal integration in the endoplasmic reticulum unfolded protein response. Nat. Rev. Mol. Cell Biol. 8, 519-529 (2007).

8. Wang, S. \& Kaufman, R. J. The impact of the unfolded protein response on human disease. J. Cell Biol. 197, 857-867 (2012).

9. Tirasophon, W., Welihinda, A. A. \& Kaufman, R. J. A stress response pathway from the endoplasmic reticulum to the nucleus requires a novel bifunctional protein kinase / endoribonuclease (Irelp) in mammalian cells. Genes Dev. 12, 1812-1824 (1998).

10. Calfon, M. et al. IRE1 couples endoplasmic reticulum load to secretory capacity by processing the XBP-1 mRNA. Nature 415, 92-96 (2002).
11. Lee, A.-H., Iwakoshi, N. N. \& Glimcher, L. H. XBP-1 regulates a subset of endoplasmic reticulum resident chaperone genes in the unfolded protein response. Mol. Cell. Biol. 23, 7448-7459 (2003).

12. Shaffer, A. L. et al. XBP1, downstream of Blimp-1, expands the secretory apparatus and other organelles, and increases protein synthesis in plasma cell differentiation. Immunity 21, 81-93 (2004).

13. Hollien J, Weissman JS. Decay of endoplasmic reticulum-localized mRNAs during the unfolded protein response. Science, 313, 104-107 (2006).

14. Urano, F. et al. Coupling of stress in the endoplasmic reticulum to activation of JNK protein kinases by transmembrane protein kinase IRE1. Science 287, 664-666 (2000).

15. Hetz, C. et al. Proapoptotic BAX and BAK modulate the unfolded protein response by a direct interaction with IRE1alpha. Science 312, 572-576 (2006)

16. Liu, ChuanYin, Schroder, M. \& Kaufman, R. J. Ligand-independent dimerization activates the stress response kinases IRE1 and PERK in the lumen of the endoplasmic reticulum. J. Biol. Chem. 275, 24881-24885 (2000).

17. Okada, T., Yoshida, H., Akazawa, R., Negishi, M. \& Mori, K. Distinct roles of activating transcription factor 6 (ATF6) and double-stranded RNA-activated protein kinase-like endoplasmic reticulum kinase (PERK) in transcription during the mammalian unfolded protein response. Biochem. J. 366, 585-594 (2002).

18. Schröder, M. \& Kaufman, R. J. Divergent roles of IRE1alpha and PERK in the unfolded protein response. Curr. Mol. Med. 6, 5-36 (2006).

19. Kokame, K., Kato, H. \& Miyata, T. Identification of ERSE-II, a new cis-acting element responsible for the ATF6-dependent mammalian unfolded protein response. J. Biol. Chem. 276, 9199-9205 (2001).

20. Gass, J. N., Gifford, N. M. \& Brewer, J. W. Activation of an unfolded protein response during differentiation of antibody-secreting B cells*. J. Biol. Chem. 277, 49047-49054 (2002).

21. Kamimura, D. \& Bevan, M. J. Endoplasmic reticulum stress regulator XBP-1 contributes to effector $\mathrm{CD} 8+\mathrm{T}$ cell differentiation during acute infection. $J$. Immunol. 181, 5433-5441 (2008).

22. Scheu, S. et al. Activation of the integrated stress response during $\mathrm{T}$ helper cell differentiation. Nat. Immunol. 7, 644-651 (2006).

23. Iwawaki, T., Akai, R., Kohno, K. \& Miura, M. A transgenic mouse model for monitoring endoplasmic reticulum stress. Nat. Med. 10, 98-102 (2004).

24. Van Gassen, S. et al. FlowSOM: using self-organizing maps for visualization and interpretation of cytometry data. Cytom. Part A 87, 636-645 (2015).

25. Godfrey, D. I., Stankovic, S. \& Baxter, A. G. Raising the NKT cell family. Nat. Immunol. 11, 197-206 (2010).

26. Drennan, M. B. et al. The thymic microenvironment differentially regulates development and trafficking of invariant NKT cell sublineages. J. Immunol. 193, 5960-5972 (2014).

27. Lee, Y. J., Holzapfel, K. L., Zhu, J., Jameson, S. C. \& Hogquist, K. A. Steadystate production of IL-4 modulates immunity in mouse strains and is determined by lineage diversity of iNKT cells. Nat. Immunol. 14, 1146-1154 (2013).

28. Tyznik, A. J. et al. Cutting edge: the mechanism of invariant NKT cell responses to viral danger signals. J. Immunol. 181, 4452-4456 (2008).

29. Paget, C. et al. Activation of invariant NKT cells by Toll-like receptor 9 stimulated dendritic cells requires type I interferon and charged glycosphingolipids. Immunity 27, 597-609 (2007).

30. Zhang, K. et al. The unfolded protein response sensor IRElalpha is required at 2 distinct steps in B cell lymphopoiesis. J. Clin. Invest. 115, 268-281 (2005).

31. Kemp, K. L. \& Lin, Z. The serine-threonine kinase inositol-requiring enzyme 1 alpha (IRE1 alpha) promotes IL-4 production in T helper cells. J. Biol. Chem. 288, 33272-33282 (2013).

32. Geissmann, F. et al. Intravascular immune surveillance by CXCR6 + NKT cells patrolling liver sinusoids. PLoS Biol. 3, el13 (2005).

33. Iwawaki, T., Akai, R., Yamanaka, S. \& Kohno, K. Function of IRE1 alpha in the placenta is essential for placental development and embryonic viability. Proc. Natl Acad. Sci. USA 106, 16657-16662 (2009).

34. Drennan, M. B. et al. NKT sublineage specification and survival requires the ubiquitin-modifying enzyme TNFAIP3/A20. J. Exp. Med. 213, 1973-1981 (2016).

35. Wang, L. et al. Divergent allosteric control of the IRE1 a endoribonuclease using kinase inhibitors. Nat. Chem. Biol. 8, 982-989 (2012).

36. Tang, C. A. et al. Inhibition of ER stress-associated IRE-1/XBP-1 pathway reduces leukemic cell survival. J. Clin. Invest. 124, 2585-2598 (2014).

37. Qiu, Q. et al. Toll-like receptor-mediated IREl $\alpha$ activation as a therapeutic target for inflammatory arthritis. EMBO J. 32, 2477-2490 (2013).

38. Nishitoh, H. et al. ASK1 is essential for endoplasmic reticulum stress-induced neuronal cell death triggered by expanded polyglutamine repeats. Genes Dev. 16, 1345-1355 (2002).

39. Kim, I. et al. Chemical biology investigation of cell death pathways activated by endoplasmic reticulum stress reveals cytoprotective modulators of ASK1* J. Biol. Chem. 284, 1593-1603 (2009). 
40. Chen, C., Del Gatto-konczak, F., Wu, Z. \& Karin, M. Stabilization of Interleukin2 mRNA by the c-Jun NH2 -terminal kinase pathway. Science (80-.) 280 , 1945-1949 (1998).

41. Guo, L., Urban, J. F., Zhu, J. \& Paul, W. E. Elevating calcium in Th2 cells activates multiple pathways to induce IL-4 transcription and mRNA stabilization. J. Immunol. 181, 3984-3993 (2008).

42. Stebbins, J. L. et al. Identification of a new JNK inhibitor targeting the JNK-JIP interaction site. Proc. Natl Acad. Sci. USA 105, 16809-16813 (2008).

43. Cuenda, A. et al. SB 203580 is a specific inhibitor of a MAP kinase homologue which is stimulated by cellular stresses and interleukin-1. FEBS Lett. 364, 229-233 (1995).

44. Heller, F., Fuss, I. J., Nieuwenhuis, E. E., Blumberg, R. S. \& Strober, W. Oxazolone colitis, a Th2 colitis model resembling ulcerative colitis, is mediated by IL-13-producing NK-T cells. Immunity 17, 629-638 (2002).

45. Boirivant, M., Fuss, I. J., Chu, A. \& Strober, W. Oxazolone colitis: a murine model of T helper cell type 2 colitis treatable with antibodies to interleukin 4 . J. Exp. Med. 188, 1929-1939 (1998).

46. Pino, S.C et al. Protein kinase $\mathrm{C}$ signaling during $\mathrm{T}$ cell activation induces the endoplasmic reticulum stress response. Cell Stress Chaperone. 13, 421-434 (2008).

47. Lee, A., Chu, G. C., Neal, N. \& Glimcher, L. H. XBP-1 is required for biogenesis of cellular secretory machinery of exocrine glands. EMBO J. 24 4368-4380 (2005).

48. Lipson, K. L. et al. Regulation of insulin biosynthesis in pancreatic beta cells by an endoplasmic reticulum-resident protein kinase IRE1. Cell Metab. 3, 245-254 (2006).

49. Reimold, A. M. et al. An essential role in liver development for transcription factor XBP-1. Genes Dev. 14, 152-157 (2000).

50. Nagaleekar, V. K. et al. Translational control of NKT cell cytokine production by p38 MAP kinase. J. Immunol. 186, 4140-4146 (2013).

51. Tiedje, C., Holtmann, H. \& Gaestel, M. The role of mammalian MAPK signaling in regulation of cytokine mRNA stability and translation. $J$. Interferon Cytokine Res. 34, 220-233 (2014).

52. Roy, B. \& Jacobson, A. The intimate relationships of mRNA decay and translation. Trends Genet. 29, 691-699 (2013).

53. Ivanov, P. Post-transcriptional regulatory networks in immunity. Immunol. Rev. 253, 253-272 (2013).

54. Govindarajan, S., Elewaut, D. \& Drennan, M. An optimized method for isolating and expanding invariant natural killer T cells from mouse spleen. J. Vis. Exp. 105, 1-7 (2015).

55. Bloch, Y. et al. Structural activation of pro-inflammatory human cytokine IL23 by cognate IL-23 receptor enables recruitment of the shared receptor IL12R 31 . Immunity.48, 45-58 (2018).

56. Favreau, M. et al. Leptin receptor antagonism of iNKT cell function: a novel strategy to combat multiple myeloma. Leukemia 31, 2678-2685 (2017).

\section{Acknowledgements}

We thank Julie Coudenys and Nadia Schryvers for aGalCer-CD1d tetramer production. We also thank Dr. James McCluskey, Dr. Jamie Rossjohn, and Dr. David Fairlie, for developing the MR1 tetramer technology and also the NIH Tetramer Core Facility for MRI tetramer production. Y.B. acknowledges pre- and post-doctoral research fellowship support from the Flanders Agency for Innovation and Entrepreneurship (VLAIO-Flanders, Belgium) and Research Foundation Flanders (FWO), respectively. S.N.S. acknowledges research support from Research Foundation Flanders (FWO grant nr. G0C2214N and 3G0B491) and the Hercules Foundation (grant nr. AUGE11-029). S.V.G. acknowledges post-doctoral fellowship from Research Foundation Flanders (FWO). Research was supported by grants from the Group-ID Multidisciplinary Platform (MRP) of Ghent University (to D.E. and M.B.D.), Stichting tegen kanker (to D.E.) and the Fund for Scientific Research-Flanders including a Excellence of Science (EOS) grant (to D.E.).

\section{Author contributions}

S.G., M.B.D., and D.E. designed the experiments. S.G. performed the experiments and co-wrote the manuscript. D.G., R.V.d.C., E.V., S.T. performed the experiments. S.V.G. and Y.S. helped with the flow cytometry analysis. T.I., Y.B., and S.N.S. provided the reagents. S.J., B.N.L., M.B.D., and D.E. supervised the work and wrote the manuscript.

\section{Additional information}

Supplementary Information accompanies this paper at https://doi.org/10.1038/s41467018-07758-x.

Competing interests: The authors declare no competing interests.

Reprints and permission information is available online at http://npg.nature.com/ reprintsandpermissions/

Journal peer review information: Nature communications thanks the anonymous reviewers for their contribution to the peer review of this work.

Publisher's note: Springer Nature remains neutral with regard to jurisdictional claims in published maps and institutional affiliations.

cc) (i) Open Access This article is licensed under a Creative Commons BY Attribution 4.0 International License, which permits use, sharing adaptation, distribution and reproduction in any medium or format, as long as you give appropriate credit to the original author(s) and the source, provide a link to the Creative Commons license, and indicate if changes were made. The images or other third party material in this article are included in the article's Creative Commons license, unless indicated otherwise in a credit line to the material. If material is not included in the article's Creative Commons license and your intended use is not permitted by statutory regulation or exceeds the permitted use, you will need to obtain permission directly from the copyright holder. To view a copy of this license, visit http://creativecommons.org/ licenses/by/4.0/.

(C) The Author(s) 2018 